\title{
The Structural and Functional Integrity of Peripheral Nerves Depends on the Glial-Derived Signal Desert Hedgehog
}

\author{
Soheila Sharghi-Namini, ${ }^{1}$ Mark Turmaine, ${ }^{1}$ Carola Meier, ${ }^{2}$ Vishal Sahni, ${ }^{1}$ Fujio Umehara, ${ }^{3}$ Kristjan R. Jessen, ${ }^{1}$ and \\ Rhona Mirsky ${ }^{1}$ \\ ${ }^{1}$ Department of Anatomy and Developmental Biology, University College London, London WC1E 6BT, United Kingdom, ${ }^{2}$ Department of Neuroanatomy \\ and Molecular Brain Research, Ruhr-University Bochum, D-44780 Bochum, Germany, and ${ }^{3}$ Department of Neurology and Geriatrics, Kagoshima \\ University Graduate School of Medical and Dental Sciences, Kagoshima 890-8520, Japan
}

We show that desert hedgehog $(d h h)$, a signaling molecule expressed by Schwann cells, is essential for the structural and functional integrity of the peripheral nerve. Dhh-null nerves display multiple abnormalities that affect myelinating and nonmyelinating Schwann cells, axons, and vasculature and immune cells. Myelinated fibers of these mice have a significantly increased (more than two times) number of Schmidt-Lanterman incisures (SLIs), and connexin 29, a molecular component of SLIs, is strongly upregulated. Crossing dhh-null mice with myelin basic protein (MBP)-deficient shiverer mice, which also have increased SLI numbers, results in further increased SLIs, suggesting that Dhh and MBP control SLIs by different mechanisms. Unmyelinated fibers are also affected, containing many fewer axons per Schwann cell in transverse profiles, whereas the total number of unmyelinated axons is reduced by approximately one-third. In $d h h$-null mice, the blood-nerve barrier is permeable and neutrophils and macrophage numbers are elevated, even in uninjured nerves. Dhh-null nerves also lack the largest-diameter myelinated fibers, have elevated numbers of degenerating myelinated axons, and contain regenerating fibers. Transected $d h h$ nerves degenerate faster than wild-type controls. This demonstrates that a single identified glial signal, Dhh, plays a critical role in controlling the integrity of peripheral nervous tissue, in line with its critical role in nerve sheath development (Parmantier et al., 1999). The complexity of the defects raises a number of important questions about the Dhhdependent cell-cell signaling network in peripheral nerves.

Key words: glia; degeneration; regeneration; hedgehog; PNS; electron microscopy; neuropathy

\section{Introduction}

It is commonly believed that signals from glial cells play an essential part, directly and indirectly, in establishing and maintaining the structural and functional integrity of the nervous system. Nevertheless, it has proved hard to identify particular signaling molecules that perform such functions in vivo and to define the consequences of their absence. Here, we have addressed this issue by examining the signaling molecule desert hedgehog (Dhh) in peripheral nerves, where this gene is expressed exclusively by myelinating Schwann cells.

Hedgehogs (Hhs) are intercellular signaling proteins that are best known for controlling tissue patterning during development. In mammals, the Hh family consists of three members: Sonic hedgehog (Shh), Indian hedgehog (Ihh), and Dhh (Ham-

Received Jan. 13, 2006; revised April 21, 2006; accepted April 24, 2006.

This work was supported by a program grant from the Wellcome Trust to K.R.J. and R.M. and by a grant from The Ministry of Education, Culture, Sports, Science, and Technology of Japan to F.U. We thank P. Brophy, S. Davies, L. Morgan, E. Peles, J. Roes, and J. Archelos for the gift of antibodies, A. P. McMahon and I. Griffiths for provision of mutant mice, L. Rubin for the gift of the hedgehog pathway agonist C67, Biogen for Desert hedgehog protein, J. Golding for discussions about statistics, Yuko Shirahama for technical assistance, Jane Pendjiky for photographic assistance, and Debbie Bartram for editing this manuscript.

Correspondence should be addressed to Dr. Rhona Mirsky, Department of Anatomy and Developmental Biology, University College London, Gower Street, London WC1E 6BT, UK. E-mail: r.mirsky@ucl.ac.uk.

D0I:10.1523/JNEUROSCI.0157-06.2006

Copyright $\odot 2006$ Society for Neuroscience $\quad$ 0270-6474/06/266364-13\$15.00/0 merschmidt et al., 1997). They bind to the transmembrane receptors patched to activate complex intracellular signaling cascades involving smoothened (smo) and the three gli transcription factors (Ruiz i Altaba et al., 2003). We have shown previously that during development, Dhh secreted by Schwann cells is required for the correct formation of the perineurial tissue sheath around peripheral nerves (Parmantier et al., 1999). In humans, a null mutation in $d h h$ also leads to peripheral neuropathy with mini-fascicle formation and gonadal dysgenesis (Umehara et al., 2000).

There is increasing recognition that long- and short-term term signaling from glial cells has an essential role in the nervous system. Glial cells are a key source not only of developmental signals and trophic factors but also of signals that regulate blood flow, neuronal survival after injury, and pain pathways (Jessen, 2004; Newman, 2004; Schipke and Kettenmann, 2004; Ullian et al., 2004; Tsuda et al., 2005). They also secrete gliotransmitters that take part in the short-term regulation of synaptic function and neuronal excitability (Zhang and Haydon, 2005).

A number of observations indicates the importance of glialderived signals in peripheral nerves. Schwann cell precursors and immature Schwann cells are likely to provide indispensable survival support for embryonic motor and sensory neurons, because removal of these glial cells through genetic manipulations results in extensive neuronal death (Garratt et al., 2000; Jessen and Mir- 
sky, 2005). In mature nerves also, disruption of the relationship between unmyelinated axons and nonmyelinating Schwann cells leads to death of sensory neurons perhaps as a result of decreased glial cell line-derived neurotrophic factor expression (Chen et al., 2003). In myelinated fibers, axonal death accompanies inherited Schwann cell disorders, pointing to a disruption of as yet unidentified signaling pathways between axons and Schwann cells, whereas at the neuromuscular junction, unknown signals from perisynaptic glia modulate synaptic activity (Colomar and Robitaille, 2004).

In the present study, we find that removal of Dhh, a signaling molecule selectively expressed in myelinating Schwann cells in adult nerves, has wide-ranging adverse consequences for every tissue component of peripheral nerves. This demonstrates an important signaling function for myelinating Schwann cells and identifies a glial signal that is essential for tissue integrity.

\section{Materials and Methods} Animals

Dhh-null mice were obtained by homologous recombination as described previously (Bitgood et al., 1996) and were made available by Prof. A. P. McMahon (Harvard University, Boston, MA). Animals were genotyped as $d h h+/+, d h h+/-$, or $d h h-/-$ by PCR on genomic DNA (Parmantier et al., 1999). The $d h h$-null mutant and wild-type mice were on a mixed CD1/C57BL6 genetic background. Myelin basic protein (MBP)deficient shiverer (shi) mice were obtained from Prof. I. Griffiths (University of Glasgow Veterinary School, Glasgow, UK). They are on a C3H/ 101 background and were genotyped as shi+/+, shi+/-, and shi-/- by PCR (Gomez et al., 1990). All conclusions are based on observations on a minimum of three animals per genotype. The number of animals in each particular test is indicated in the text.

\section{In situ hybridization}

Digoxygenin-labeled cRNA antisense probes were generated as described by Parmantier et al. (1999). Postnatal day 10 (P10) mice were perfused with $4 \%$ phosphate-buffered parafomaldehyde for $30 \mathrm{~min}$. The nerves were then removed and fixed for an additional $3 \mathrm{~h}$ with fresh $4 \%$ paraformaldehyde at $4^{\circ} \mathrm{C}$. They were rinsed in PBS and protected in $30 \%$ sucrose in PBS overnight before mounting in Tissue Tek (Sakura Finetek, Tokyo, Japan). Frozen sections $(20 \mu \mathrm{m})$ were mounted on Superfrost slides before in situ hybridization overnight at $65^{\circ} \mathrm{C}$ with a digoxygeninlabeled antisense probe to $d h h$ as described previously (Parmantier et al., 1999). Subsequently, slides were incubated overnight with antibody to human smooth muscle actin (clone 1A4; 1:70; a gift from L. Morgan, EISAI London Research, London, UK) (DakoCytomation, Carpinteria, $\mathrm{CA}$ ) and with goat anti-mouse Ig rhodamine for $1 \mathrm{~h}$ (MP Biomedicals, Irvine, CA), followed by mouse anti-MBP (1:200; Sternberger Monoclonals, Baltimore, MD) overnight and by goat anti-mouse Ig fluorescein (Jackson ImmunoResearch, West Grove, PA) for $1 \mathrm{~h}$ before being mounted in Citifluor (London, UK) anti-fade mounting medium before examination in an Eclipse 800 Nikon (Tokyo, Japan) fluorescence microscope.

\section{Labeling and analysis of Schmidt-Lanterman incisures}

Nerve fixation and immunolabeling were as described by Gould et al. (1995). Immediately after the mice were killed, the sciatic nerves were exposed from the straightened thigh and fixed in situ with $4 \%$ phosphatebuffered paraformaldehyde for $30 \mathrm{~min}$. The nerves were then removed and fixed for an additional $3 \mathrm{~h}$ with fresh $4 \%$ paraformaldehyde at $4^{\circ} \mathrm{C}$. They were rinsed in PBS and stored in newly made PBS at $4^{\circ} \mathrm{C}$. On the next day, the nerves were desheathed and cut into smaller pieces. They were teased individually into small bundles, transferred into a 96-well plate containing rhodamine-conjugated phalloidin (1:100; Sigma, St. Louis, MO), and kept overnight at $4^{\circ} \mathrm{C}$. They were then rinsed three times in PBS and transferred individually to Superfrost-coated slides, where they were teased further into single fibers and smaller bundles. Slides were then either mounted in Citifluor anti-fade mounting medium or immunolabeled with antibodies to MUPP1 (Poliak et al., 2002) (a gift from E. Peles, The Weizmann Institute of Science, Rehovot, Israel) or neurofascin (NF) 155 (Chang et al., 2000) (a gift from P. Brophy, University of Edinburgh, Edinburgh, UK) and goat anti-rabbit FITC (MP Biomedicals) before being mounted in Citifluor anti-fade mounting medium before examination in an Nikon Eclipse 800 fluorescence microscope. Connexin 29 (cx29) labeling was performed on ethanol-fixed nerves as described by $\mathrm{Li}$ et al. (2002), and $\mathrm{K}_{\mathrm{V}} 1.2$ antibody (Alomone Laboratories, Jerusalem, Israel) labeling was performed after phalloidin labeling as described by Altevogt et al. (2002). Images were captured using a digital camera at $40 \times$ magnification with Lucia acquisition software, which was also used for measurements of Schmidt-Lanterman incisures (SLIs) and fiber width. In randomly chosen fibers, the inter-SLI distance was measured from the center of one SLI to the center of the next adjacent SLI, and the fiber width was measured at three positions along the internode as described by Gould et al. (1995). The numbers of SLIs were counted along measured distances of randomly selected individual teased fibers. Measurements were taken from fibers from two animals of each genotype at each time point. A total of 1311 SLI intervals was measured in $d h h-/-$ fibers, 689 in $d h h+/-$ fibers, and 221 in $d h h+/+$ fibers (P10 only). For counts of the number of SLIs, a total of 133 fibers was analyzed in $d h h-/-$ mice, 138 in $d h h+/-$ mice, and 51 in $d h h+/+$ mice (P10 only).

\section{Electron microscopic analysis of tissue sections}

P30 $d h h+/+, d h h+/-$, and $d h h-/-$ mice ( $n=3$ per genotype) were anesthetized and perfused with $4 \%$ paraformaldehyde and $2.5 \%$ glutaraldehyde in $0.1 \mathrm{M}$ phosphate buffer.

Analysis of nerve fiber diameter. Sciatic nerves were removed and postfixed in the same solution at $4^{\circ} \mathrm{C}$ overnight. They were then processed for electron microscopy as described previously (Parmantier et al., 1999). Ultrathin transverse sections were viewed and photographed using a JEOL (Peabody, MA) 1010 electron microscope. Pictures were taken from the lower right quadrant of transverse sections at $2000 \times$ magnification, covering in total one-fourth of the entire nerve area. They were scanned and imported into Open Lab software, where the diameter of myelinated axons and of myelin plus axons was measured. From these measurements, the g-ratio (axon diameter/axon plus myelin sheath diameter) was calculated. To study the size distribution of axons and of axons plus myelin, the measurements were grouped into increasing size categories separated by $0.1 \mu \mathrm{m}$, and the number in each category was determined.

Nonmyelinating Schwann cells. Using the sections and micrographs taken for the previous analysis, the number of unmyelinated axons/ Schwann cell unit was counted in two 2-month-old and one 4-monthold animal of each genotype, and the number of axons in a 1:1, 2:1, etc., ratio was expressed as a percentage of the total number of unmyelinated axons.

Axon numbers in the tibial branch. The total number of myelinated and unmyelinated axons in the entire tibial branch of the sciatic nerve was counted directly in the electron microscope using sections mounted on membrane-coated grids without grid bars. Nerves from 2-, 4-, and 5.5month-old $d h h+/+$ and $d h h-/-$ littermates were counted $(n=3$ nerves for each genotype).

Degeneration and regeneration in uninjured sciatic nerve. $d h h+/+$ and dhh $-/-$ mice aged 2-6 months (two mice per genotype) and 21 months (two mice per genotype) were perfused with $2.5 \%$ paraformaldehyde and $2.5 \%$ glutaraldehyde in $0.1 \mathrm{~m}$ phosphate buffer. Sciatic nerves were dissected and processed for electron microscopy as before. Photographic $(500 \times)$ montages covering a transverse section of the entire tibial and common peroneal branches at the mid-thigh level from each animal were analyzed. Degenerating fibers were identified as profiles either without an axon or with a highly reduced axon caliber in association with obviously broken myelin. The regenerating myelinated fibers were identified by the presence of loose, redundant basal lamina and a reduced number of myelin lamellae (usually $<10$ lamellae) relative to axon diameter. The sections were also observed at higher magnification to confirm the data. 
The number of compact and interrupted myelinated fibers. Photographic montages were made as described above, including the tibial and common peroneal branch of the sciatic nerve, and the entire nerve profiles were analyzed (three animals per genotype).

Degeneration after nerve cut. The left sciatic nerve from 2-month-old $d h h+/-$ and $d h h-/-$ mice was transected $(n=2$ per genotype per time point). At 2 and $7 \mathrm{~d}$ after operation, mice were perfused and the nerves were processed for electron microscopy. The right sciatic nerve from each animal was used as a control. Sections were taken at approximately mid-thigh level, and photographic montages of transverse sections were made as described above. Fibers in both uncut and $2 \mathrm{~d}$ postcut nerve were categorized into (1) normal-looking fibers with intact myelin, (2) fibers with collapsed axons, and (3) fibers with collapsed myelin. The entire section of each nerve was counted. In parallel experiments, nerves were processed for immunoblotting (see below).

\section{Measurement of motor neuron cell body size}

$\mathrm{P} 30 d h h+/+, d h h+/-$, and $d h h-/-$ mice were perfused with $4 \%$ paraformaldehyde, $4 \%$ picric acid, and $0.15 \mathrm{~m}$ phosphate buffer. The spinal cord was exposed, and the tissue from lumbar (L) levels L4-L5 was further dissected and postfixed for $1 \mathrm{~h}$. Segments were washed in $0.1 \mathrm{M}$ phosphate buffer before overnight incubation in $30 \%$ sucrose/PBS at $4^{\circ} \mathrm{C}$. Forty-micrometer sections were cut transversely on a freezing microtome and transferred individually into wells of a 96-well plate containing $0.1 \mathrm{~m}$ phosphate buffer, $5 \%$ sucrose, and $0.02 \%$ sodium azide. The sections were transferred onto gelatinized slides and allowed to dry for $24 \mathrm{~h}$ before 4-6 min immersion in Neutral Red solution $(0.5 \%$ in $1 \%$ acetic acid). Slides were dehydrated, mounted in DPX mounting medium (BDH Chemicals, Poole, UK), and observed at $20 \times$ in a Nikon Eclipse 800 microscope. Images of sections were captured using a digital camera and AKT software (Nikon), and the area of the cell soma of individual motor neurons was measured using Open Lab software.

\section{Immunoblotting}

Proteins were extracted from sciatic nerves of $d h h+/-$ and $d h h-/-$ mice as described by Wrabetz et al. (2000). Samples were denatured and resolved on either $12 \%$ or $8 \%$ SDS-polyacrylamide gels and transferred onto Hybond-ECL nitrocellulose membrane (Amersham Biosciences, Piscataway, NJ). The blot was blocked with $0.05 \%$ Tween and $5 \%$ dry milk in PBS overnight at $4^{\circ} \mathrm{C}$, followed by incubation in appropriate antibody in $0.05 \%$ Tween and $1 \%$ dry milk in PBS overnight at $4^{\circ} \mathrm{C}$. Rabbit polyclonal $\mathrm{P}_{0}$ antibodies (Morgan et al., 1991) or mouse monoclonal antibodies recognizing $\mathrm{P}_{0}$ (Archelos et al., 1993) (a gift from J. J. Archelos, Karl-Franzens University, Graz, Austria), MBP, MAG (Roche Products, Welwyn Garden City, UK), $\beta$-catenin, E-cadherin (BD Biosciences, Franklin Lakes, NJ), and $\beta$-tubulin (Sigma) were used. Goat anti-mouse Ig peroxidase or goat anti-rabbit Ig peroxidase (Promega, Madison, WI) were used as second layers.

Specific protein complexes were developed using ECL-plus chemiluminescent reagent and $\mathrm{x}$-ray film (Amersham Biosciences). In some experiments, uncut and transected nerves, $2 \mathrm{~d}$ after transection, were immunoblotted with antibodies to TUJ1 (Covance, Princeton, NJ) or $\mathrm{P}_{0}$. Antibodies to glyceraldehyde-3-phosphate dehydrogenase (GAPDH; Abcam, Cambridge, MA) were used to control for equal loading of samples.

\section{Semiquantitative reverse transcription- $P C R$}

Total RNA was extracted from freshly dissected sciatic nerves from $d h h+/-$ and $d h h-/-$ mice of different ages, or from purified Schwann cells or fibroblasts, with Trizol reagent (Invitrogen, San Diego, CA) according to the manufacturer's instructions. The RNA was quantified, and $500 \mathrm{ng}$ of each was reverse transcribed into cDNA, as described previously (Parmantier et al., 1999). To check that the same quantity of cDNA was used in the PCRs, the relative amount of cDNA synthesized from each sample was assessed by PCR amplification using specific primers for GAPDH. One microliter of cDNA was used in each $50 \mu \mathrm{l}$ PCR. For the sciatic nerve extracts, reactions were cycled through one cycle at $94^{\circ} \mathrm{C}$ for $3 \mathrm{~min}$, followed by 30 rounds (27 for GAPDH) at $94^{\circ} \mathrm{C}$ for $30 \mathrm{~s}, 62^{\circ} \mathrm{C}$ (MBP, MAG, cx32, S100) for $30 \mathrm{~s}, 55^{\circ} \mathrm{C}\left(\mathrm{cx} 29\right.$ and JAM) for $45 \mathrm{~s}, 63^{\circ} \mathrm{C}$
(GAPDH) for $30 \mathrm{~s}, 72^{\circ} \mathrm{C}$ for $30 \mathrm{~s}$, and one final extension at $72^{\circ} \mathrm{C}$ for 5 min. The primer pairs were as follows: MBP: forward primer $5^{\prime}$ ACTCACACACGAGAACTACCCA3', reverse primer 5'CCAGCTAAATCTGCTGAGGG 3' (169 bp) (Nicholson et al., 2001); MAG: forward primer 5'GGAGACCTGGGCCTACGAAA3', reverse primer 5'GACGTCCAAACTGGCGTAAC3' (442 bp) (Nicholson et al., 2001); cx32: forward primer 5'TACGTGGCGTGAATCGGCAC3', reverse primer 5'GTTGGTGAGCTACGTGCATT3' (266 bp) (Nicholson et al., 2001); cx29: forward primer 5'ATGTGCGGCAGGTTCCTGAGACA3', reverse primer 5'TCAAAATGGCTCTTTTGCCTCCA3' (777 bp) (Sohl et al., 2001); S100: forward primer 5'GGTGACAAGCACAAGCTGAA3', reverse primer 5'CTGGAAGTCACACTCCCCA3' (150 bp) (Nicholson et al., 2001); JAM2: forward primer 5'GTCGCACAGATGTGTTTGG3', reverse primer 5'GAGTTCACATGGAAAGAGG3' (327 bp); JAM3: forward primer 5'TTGGTCTACTACCAACAGG3', reverse primer 5'TTTCGTGTTCATTGTGTACG3' (369 bp). For Ptc1 reverse transcription (RT)-PCR of Schwann cells, $1 \mu \mathrm{l}$ of cDNA was used in a $50 \mu \mathrm{l}$ PCR mixture that was subjected to one cycle at $94^{\circ} \mathrm{C}$ for $3 \mathrm{~min}$, followed by 35 cycles at $94^{\circ} \mathrm{C}$ for $30 \mathrm{~s}, 55^{\circ} \mathrm{C}$ for $1 \mathrm{~min}, 72^{\circ} \mathrm{C}$ for $30 \mathrm{~s}$, and one final extension at $72^{\circ} \mathrm{C}$ for $5 \mathrm{~min}$ [Ptcl: forward primer $5^{\prime}$ AACAAAAATTCAACCAAACCTC3', reverse primer 5'TGTCTTCATTCCAGTTGATGTG3' (244 bp) (Takabatake et al., 1997); Cld5: forward primer 5'GAAGGGGCTGTGGATGTC3', reverse primer 5'ACCGTCGGATCATAGAAC3' (314 bp) (Poliak et al., 2002)].

\section{Preparation of purified neonatal mouse Schwann cells}

P3 nerve Schwann cells from ICR mice were purified by immunopanning using antibodies to Thy-1 as described previously (Dong et al., 1999). Schwann cells were plated on to $35 \mathrm{~mm}$ poly-L-lysine- and laminincoated tissue culture dishes in defined medium with low insulin (Dong et al., 1999), D-glucose, and $10 \mathrm{ng} / \mathrm{ml}$ neuregulin- $\beta 1$ (R \& D Systems, Minneapolis, MN). Twenty-four hours before the experiment, the Schwann cell medium was changed to DMEM and 10\% fetal calf serum (Invitrogen). Cells were then treated with the Hh pathway agonist Cur-0199567 (C67) (40 nм; a gift from Dr. L. Rubin, Curis, Cambridge, MA) (FrankKamenetsky et al., 2002). Fibroblasts were treated with recombinant human Dhh protein (a gift from Biogen, Cambridge, MA). Three and $24 \mathrm{~h}$ later, RNA was extracted as described above.

\section{Labeling of macrophages and neutrophils}

The left sciatic nerves from 2-month-old $d h h+/-$ and $d h h-/-$ mice were transected. The mice were killed at $2 \mathrm{~d}$ after operation, and the distal stumps of cut nerve and the uncut sciatic nerve from each animal were fresh frozen in Tissue Tek (Sakura Finetek). Frozen sections $(10 \mu \mathrm{m})$ of $d h h+/-$ and $d h h-/-$ nerves were fixed with $4 \%$ paraformaldehyde and labeled with F4/80 antibody (Serotec, Indianapolis, IN) (a gift from S. Davies, University College London, London, UK) to identify macrophages (Starkey et al., 1987) and Ly-6G (GR1)-FITC antibody (BD Biosciences) (a gift from J. Roes, University College London, London, UK) to identify neutrophils (Parmantier et al., 1999).

\section{Endoneurial blood vessel permeability}

Five percent bovine albumin (Cohn fraction V) was mixed with $1 \%$ Evans blue albumin (EBA) in HBSS (Sigma) and dialyzed against HBSS overnight at $4^{\circ} \mathrm{C}$ (Kristensson and Olsson, 1971). The following day, the tracer was filtered, and $1 \mathrm{ml} / \mathrm{kg}$ body weight of mice (P30) was injected into the jugular vein of anesthetized mice $(n=3$ per genotype). The tracer was left to circulate for $3 \mathrm{~h}, 30 \mathrm{~min}$ before the mice were killed, and the sciatic nerve and the brain from each animal were fixed with $4 \%$ paraformaldehyde, sectioned, and viewed under the fluorescence microscope.

\section{Results}

\section{The number of SLI is elevated in dhh-/- Schwann cells}

We previously used teased nerve fiber preparations to show that in postnatal nerves $d h h$ is selectively expressed by myelinating Schwann cells (Parmantier et al., 1999). We confirmed this finding using in situ hybridization on transverse sections of P10 sciatic nerve because this allows visualization of other 

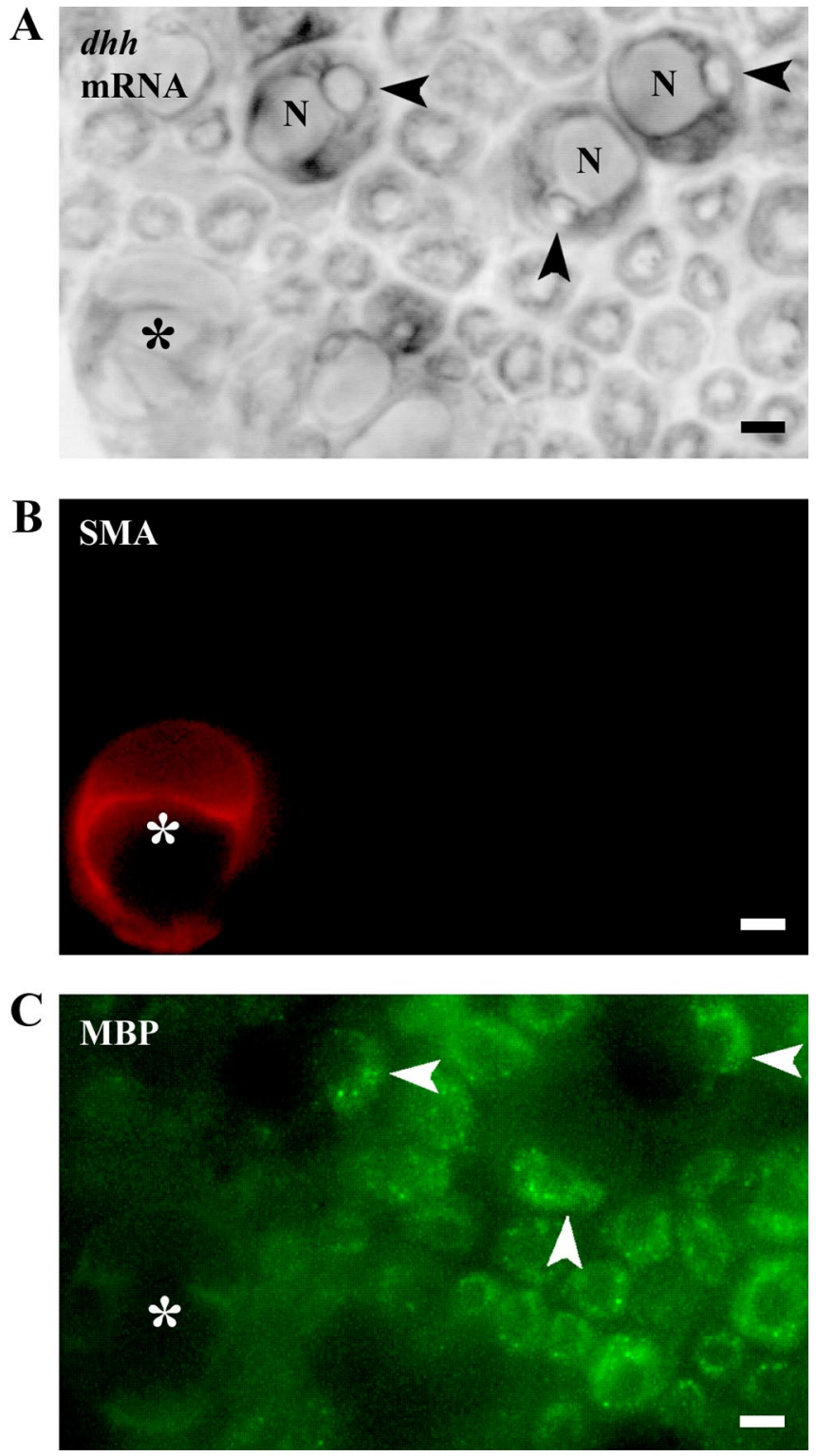

Figure 1. Dhh mRNA is selectively expressed in myelinating Schwann cells. The same field from a transverse section of a P10 sciatic nerve is shown in $\boldsymbol{A}$ (bright field to visualize dhh mRNA by in situ hybridization), $\boldsymbol{B}$ (immunofluorescence to visualize blood vessels), and $\boldsymbol{C}$ (immunofluorescence to visualize myelin). $\boldsymbol{A}$, Unambiguous Dhh signal is only seen where the section cuts through the nuclei $(N)$ of myelinating cells displacing the myelin sheath (arrowheads) to an eccentric position. $B$, The field contains one capillary (asterisk) visualized by smooth muscle actin (SMA) antibodies. C, Myelin sheaths shown by MBP antibodies. Myelin sheaths associated with Schwann cell nuclei that are labeled for $d h h$ mRNA (arrowheads). Asterisk in $\boldsymbol{A}$ and $\boldsymbol{C}$ indicates a capillary. Scale bars, $4 \mu \mathrm{m}$.

cellular components of the nerve, including blood vessels and the perineurium, both of which were essentially negative (Fig. 1).

To investigate the effect of Dhh on the general architecture of myelinated fibers, nerves were taken from $d h h+/-$ and $d h h-/-$ mice at P10, P23, P30, and 8 months $(n=2$ for each genotype at each age), fixed, teased, and stained with fluorescein-conjugated phalloidin, which binds to F-actin and clearly demarcates nodes of Ranvier, paranodal loops, and SLIs, which are cytoplasmic channels within compact myelin that are considered to facilitate communication between the cytoplasmic compartments on abaxonal and adaxonal sides of the myelin sheath via gap junctions
A

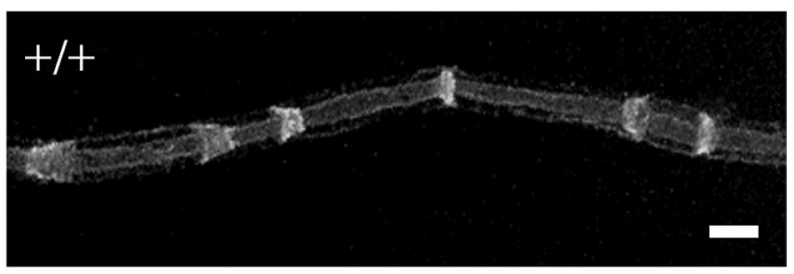

B

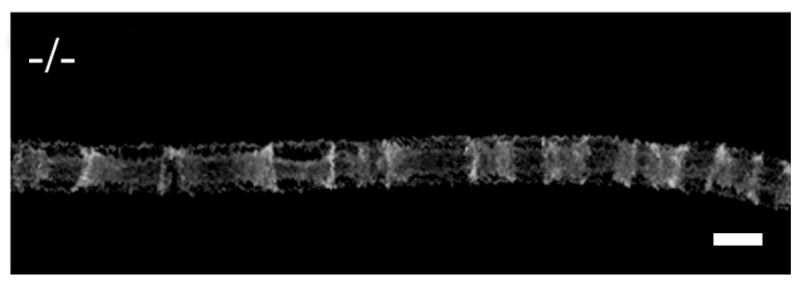

Figure 2. Teased nerve fibers of $d h h-/-$ mice, labeled with rhodamine-conjugated phalloidin, show increased numbers of SLls in a $d h h+/-$ nerve fiber $(\boldsymbol{A})$ and in a $d h h-/-$ nerve fiber $(\boldsymbol{B})$. Note also the increased size and complexity of the SLI in $\boldsymbol{B}$. Scale bar, $10 \mu \mathrm{m}$.

(Hall and Williams, 1970; Ghabriel and Allt, 1981; Trapp et al., 1989; Gould et al., 1995; Balice-Gordon et al., 1998; Poliak and Peles, 2003). Examination of $d h h+/+$, $d h h+/-$, and $d h h-/-$ fibers revealed an obvious increase in SLI numbers in the $d h h-/-$ animals (Fig. 2; see Fig. 5). This was quantified by measuring distances between SLIs (Gould et al., 1995). This showed that the distance between SLIs in $d h h-/-$ fibers was about onehalf of that in $d h h+/+$ or $d h h+/-$ fibers (Table 1 ). We also counted the number of SLIs along internodes at P10, P23, and P30 and found that the number of SLIs per $100 \mu \mathrm{m}$ in $d h h-/-$ fibers was about twice that seen in controls (Table 1). The number of SLIs in $d h h+/+$ and $d h h+/-$ mice was similar showing that a single copy of $d h h$ is sufficient to maintain the normal SLI phenotype. Because the number of SLIs was increased, the distance between SLIs was decreased (Table 1). When visualized by phalloidin labeling, the gross morphology of SLIs in $d h h-/-$ nerves differed from that of normal nerves. Whereas the majority of SLIs in normal fibers were relatively simple structures, those in $\mathrm{dhh}-/ \mathrm{-}$ fibers were frequently broader and more complex, often consisting of closely spaced doublets (Fig. 2). Similar observations were made in shi mice, where the number of SLIs is also increased as a result of lack of MBP (Gould et al., 1995).

\section{Electron microscopic analysis shows a decreased number of large fibers in $\mathbf{d h h}-/-$ mice}

To test whether the absence of Dhh changed other structural features of myelinated fibers, electron micrographs from the sciatic nerves of $d h h+/+, d h h+/-$, and $d h h-/-$ mice $(n=3$ per genotype) were scanned, and the diameter of axons and axons plus myelin of $>1000$ fibers for each genotype was measured. We found that the number of larger-diameter myelinated axons was reduced in $d h h-/-$ mice compared with $d h h+/-$ mice (Fig. $3 A$ ). In these nerves, the number of axons between 6.0 and $7.5 \mu \mathrm{m}$ in diameter was significantly reduced ( $p<0.05$; KolmogorovSmirnov $Z$ test) and larger axons were absent. We did not find a statistically significant difference between any of the genotypes in the average diameter of axons or in the diameter of axons plus myelin (Fig. 3B), although there was a trend toward smaller diameters in $d h h-/-$ nerves. This is in line with our previous light microscopic observations on myelinated units in $d h h-/-$ and $d h h+/+$ nerves (Bajestan et al., 2006). There were no significant differences between $d h h+/+, d h h+/-$, and $d h h-/-$ nerves in the g-ratios of myelinated axons at any diameter This accords 
Table 1. The number of SLI in $d h h-/-$ and control nerves

\begin{tabular}{|c|c|c|c|c|c|c|c|}
\hline & \multicolumn{3}{|l|}{ P10 } & \multicolumn{2}{|l|}{$\mathrm{P} 23$} & \multicolumn{2}{|l|}{ P30 } \\
\hline & $d h h+/+$ & $d h h+/-$ & $d h h-/-$ & $d h h+/-$ & $d h h-/-$ & $d h h+/-$ & $d h h-/-$ \\
\hline Fiber width & $5.76 \pm 0.92$ & $5.62 \pm 0.93$ & $5.14 \pm 0.77$ & $7.48 \pm 0.11$ & $7.42 \pm 0.11$ & $8.22 \pm 0.94$ & $6.14 \pm 0.14$ \\
\hline Distance between SLIs & $37.2 \pm 1.70$ & $38.3 \pm 1.58^{\mathrm{ns}}$ & $20.12 \pm 0.61^{*, * *}$ & $39.69 \pm 1.91$ & $20.30 \pm 0.56^{*}$ & $38.29 \pm 1.09$ & $16.88 \pm 0.39^{*}$ \\
\hline $\mathrm{SLI} / 100 \mu \mathrm{m}$ & $2.38 \pm 0.11$ & $2.39 \pm 0.14^{\mathrm{ns}}$ & $4.74 \pm 0.20^{* \text { **** }}$ & $2.54 \pm 0.14$ & $5.5 \pm 0.51^{*}$ & $2.79 \pm 0.12$ & $6.38 \pm 0.39^{*}$ \\
\hline
\end{tabular}

At all ages, the distance between SLIs in $d h h-/-$ fibers is approximately one-half that seen in $d h h+/+$ or $d h h+/-$ nerves. Fiber width and distance is expressed in micrometers. The mean value \pm SEM is shown. Superscripts indicate significant difference from same age control: ${ }^{*} p<0.001$ versus $d h h+/-; * * 0<0.001$ versus $d h h+/+{ }^{\text {ns }}$ Not significant versus dhh $+/+$ (Mann-Whitney test).

with previous light-microscopic measurements of average g-ratios in $d h h+/+$ and $d h h-/-$ mice (Bajestan et al., 2006), indicating that although there are more incisures in $d h h-/-$ nerves, the myelin thickness in most individual axons remains unaltered (Fig. 3C). To determine whether the total number of myelinated axons was altered in the absence of Dhh, we used the electron microscope to count the myelinated axons in the tibial branch of the sciatic nerve in three pairs of $d h h+/+$ and $d h h-/-2$ - to 6-month-old littermates. In $d h h+/+$ mice, there were $2765 \pm 39.15$ myelinated axons, and in $d h h-/-$, mice there were $2344.67 \pm 33.33$ myelinated axons. Comparison revealed that there was a small but significant ( $p<0.05$; Student's $t$ test) drop in the number of myelinated axons in $d h h-/-$ animals.

Motor neuron number and cell body size are unchanged in $\mathbf{d h} \boldsymbol{h}-/-$ mice The largest-diameter axons within the sciatic nerve include those of motor neurons. We therefore investigated whether the observed loss of large-diameter axons in $d h h-/-$ nerves was attributable to a loss or change in the size of the motor neurons.

We compared the number and average area of the cell body of motor neurons, as judged by Neutral Red staining, in the L4/5 region of the spinal cord where the largest motor neurons are located. There was no significant difference in the average size of the motor neurons between $d h h-/-$ and $d h h+/-$ mice $(2.9 \pm 0.12 \mu \mathrm{m}$ in $d h h+/+$ and $3.2 \pm 0.1 \mu \mathrm{m}$ in $d h h-/-)$. The average number of motor neurons in the two genotypes was also similar (data not shown).

\section{A}

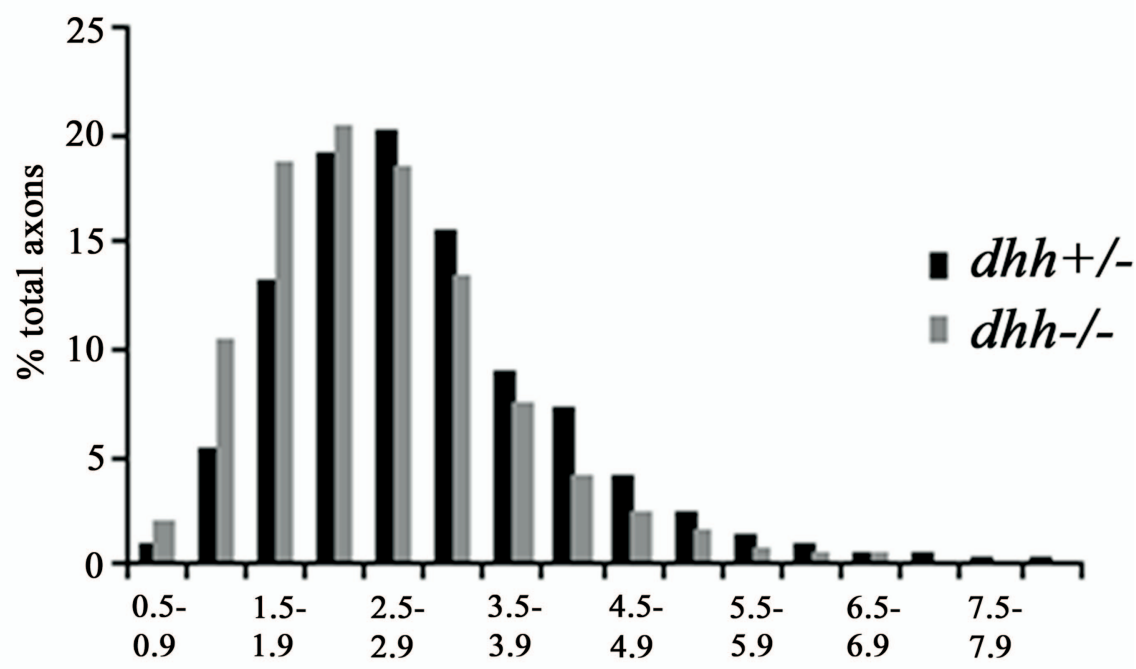

Axon diameter $/ \mu \mathrm{m}$

B
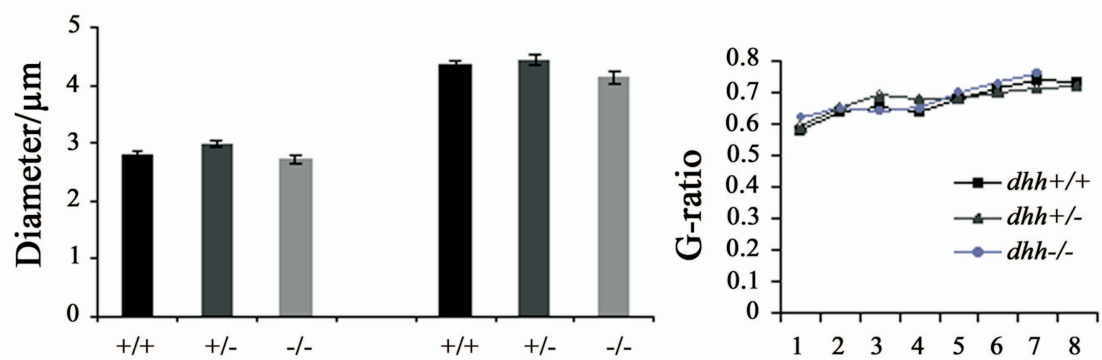

Axon
$\mathrm{C}$

Fiber diameter $/ \mu \mathrm{m}$

Figure 3. Analysis of myelinated axon and fiber diameters. $\boldsymbol{A}$, Axon diameters in $d h h+/-$ and $d h h-/-$ nerves. Note that myelinated axons of the largest diameter are absent in $d h h-/-$ nerves. $\boldsymbol{B}$, Average diameters of $d h h+/+, d h h+/-$, and $d h h-/-$ axons and myelinated profiles are similar, although the $d h h-/-$ myelinated profiles are slightly but not significantly smaller. $\boldsymbol{C}$, The g-ratio for each fiber size is similar in all three genotypes.

\section{cx29 is strongly upregulated in}

\section{dhh-/- nerves}

Because the number of SLIs was at least double in $d h h-/-$ mice at all ages, we investigated whether this increase in number had any effect on the expression levels of myelin proteins $\left(\mathrm{P}_{0}\right.$ and $\mathrm{MBP}$ ) or proteins that are expressed in the incisures (MAG, E-cadherin, $\beta$-catenin, and cx29) (Gould et al., 1995; SmithSlatas and Barbarese, 2000; Meier et al., 2004). Protein extracts were prepared from $d h h+/-$ and $d h h-/-$ mouse sciatic nerves at different ages (P10, P21, P30, and 3 months) and analyzed by immunoblotting (Fig. 4A). In $d h h-/-$ nerves, the level of MBP was somewhat lower at P30 and 3 months than in $d h h+/-$ nerves, but there was no apparent difference at earlier ages even though the difference in SLI number is already established by P10 (Table 1). There were minimal differences in the expression levels of $\mathrm{P}_{0}, \mathrm{MAG}, \mathrm{E}$-cadherin, and $\beta$-catenin protein at any of the ages tested. Western blotting of cx29, however, revealed that this protein was markedly upregulated at P21 (Fig. 4B) and other ages (data not shown). In agreement with others, we found that cx29 protein displayed anomalous behavior on Western blotting (Altevogt et al., 2002; Li et al., 2002), showing a strong band at $\sim 60$ $\mathrm{kDa}$ and a weaker band at $\sim 30 \mathrm{kDa}$, both of which were upregulated in the $d h h-/-$ nerve. 
$\mathbf{A}$

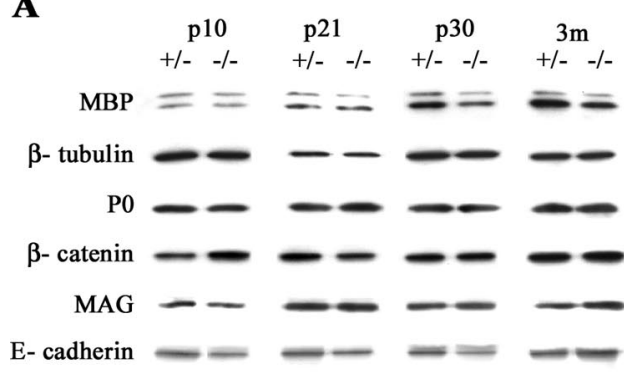

B

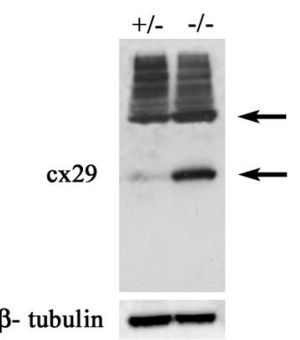

$\mathbf{C}$

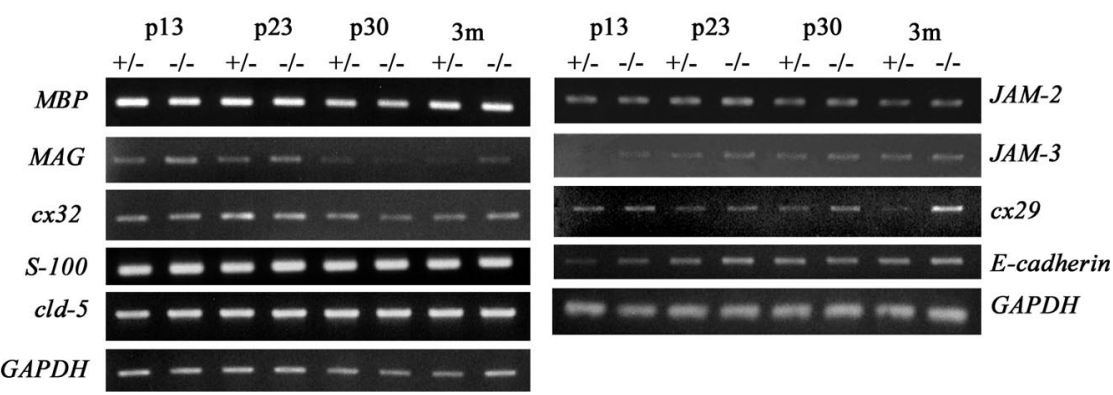

Figure 4. Western blot and RT-PCRanalysis of $d h h+/-$ and $d h h-/-$ sciaticnerves. $A$, Western blot analysis of $M B P, P_{0}, \beta$-catenin, $M A G$, and E-cadherin in sciatic nerves from $d h h+/-$ and $d h h-/-$ mice at P10, P21, P30, and 3 months. $\beta$-Tubulin is included to show that samples are equally loaded. Note that MBP levels in $d h h-/-$ nerves are lower at 3 months than in $d h h+/-$ nerves, whereas other proteins are unchanged. $\boldsymbol{B}$, Western blot analysis of $c \times 29$ at P21. Note the upregulation of a strong band at $\sim 60 \mathrm{kDa}$ and a less prominent band at $\sim 29 \mathrm{kDa}$ in the $d h h-/-$ nerves. C, RT-PCR of mRNA in sciatic nerves from $d h h+/-$ and $d h h-/-$ mice at P10, P21, P30, and 3 months of molecules that are expressed either in SLI and/or endothelial junctions. GAPDH is included to show that samples are equally loaded. Note that $\mathrm{x} 29 \mathrm{mRNA}$ levels are increased in $\mathrm{dhh}-/-$ nerve at 3 months.

$+/-$

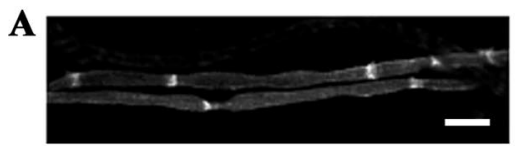

B
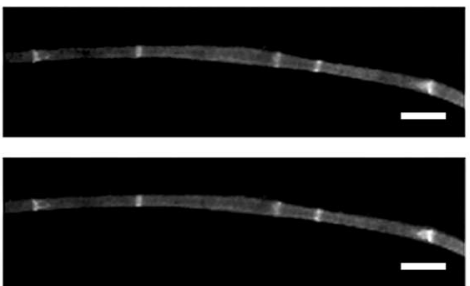

C
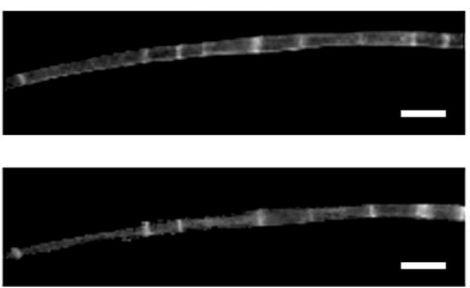

$-1-$
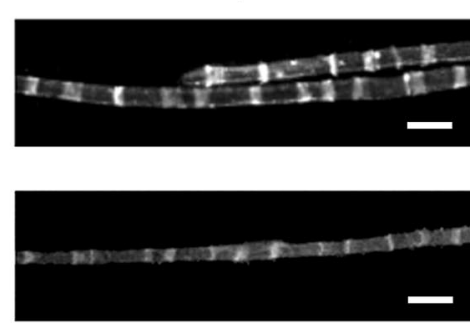

Phalloidin
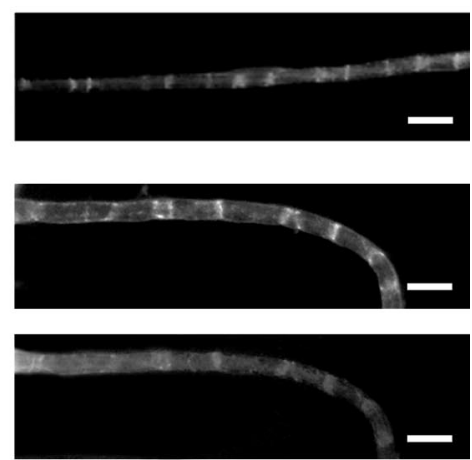

Figure 5. $\quad$ CX29, NF155, and MUPP1 are localized to SLI in nerves of both $d h h+/-$ and $d h h-/-$ mice. $A$, Sciatic nerves were teased and immunolabeled with antibodies to cx29, revealing the increased number of SLIs in the $d h h-/-$ fibers. $B$, Teased nerves were double labeled with phalloidin and antibodies to NF155, showing the increased number of SLIs in the dhh -/fibers. Note the co-incidence of actin and NF155 labeling. $\boldsymbol{C}$, Teased nerves were double labeled with phalloidin and antibodies to MUPP1. Note the co-incidence of actin and MUPP1 labeling. Scale bar, $33 \mu \mathrm{m}$.

In $\boldsymbol{d h h}$-/- mice, many SLI-associated mRNAs are unchanged, whereas cx29 mRNA levels are elevated in older nerves RT-PCR was performed on sciatic nerve extracts from $d h h+/-$ and $d h h-/-$ mice aged P10, P23, P30, and 3 months to survey the relative mRNA levels of the proteins analyzed by immunoblotting. We also investigated the mRNA levels of other proteins such as cx32, cx29, S100, and claudin5, which are associated with SLIs (Gould et al., 1995; Altevogt et al., 2002; Li et al., 2002; Poliak et al., 2002; Poliak and Peles, 2003; Meier et al., 2004), and of JAM2 and JAM3, which are associated with tight junctions and with MUPP1 (Ebnet et al., 2004). After standardization with the housekeeping gene GAPDH, samples were run separately with primers against MBP, MAG, cx32, cx29, S100, E-cadherin, claudin5, JAM2, and JAM3 (Fig. 4C). The results showed a clear increase in cx29 mRNA expression in dhh $-/-$ mice at 3 months with smaller increases detectable at all ages. The expression level of mRNAs for MBP, cx32, S100, JAM2, and JAM3 remained unchanged. MAG and E-cadherin expression levels appeared marginally higher in $\mathrm{dhh}-/-$ than $d h h+/-$ nerves at $\mathrm{P} 13$ and $\mathrm{P} 23$ but did not appear to be different at older ages.

The SLI-associated proteins MUPP1, $\mathrm{NF} 155$, and cx29 are expressed in the additional SLIs of $d h h-/-$ Schwann cells To test whether the additional SLIs present in $d h h-/-$ fibers had the same molecular composition as SLIs in normal fibers, sciatic nerves from adult $d h h+/-$ and $d h h-/-$ animals were teased and immunolabeled with antibodies against a number of SLI proteins. The localization of cx29, NF155, and MUPP1 is shown in Figure 5. MUPP1 is primarily confined to SLIs (Poliak et al., 2002), whereas cx29 and NF155 are also present in paranodal loops adjacent to the node of Ranvier. We found that NF155 and MUPP1 were seen in essentially all phalloidin-labeled SLIs in both $d h h+/+$ and $d h h-/-$ nerve fibers, and immunolabeling for $\mathrm{cx} 29$ showed a similar distribution (Fig. 5). Comparable results were obtained with S100 and MAG antibodies (data not shown). Thus, the new incisures that are generated in the absence of Dhh signaling appear to have an essentially normal molecular composition.

It has been suggested that there is an association between cx29 in myelinating Schwann cells and $\mathrm{K}_{\mathrm{V}} 1.2$ potassium channels in axonal membranes (Arroyo et al., 1999; Altevogt et al., 2002). We therefore used antibodies and immunolabeling to examine $\mathrm{K}_{\mathrm{V}} 1.2$ channels in $d h h-/-$ teased nerves (data not shown). In three separate experiments, we found that axonal $\mathrm{K}_{\mathrm{V}} 1.2$ immunolabeling was generally weaker in $d h h-/-$ fibers than in $d h h+/-$ ones. This may not be quantitatively significant. On the other hand, it is clear that $\mathrm{K}_{\mathrm{V}} 1.2$ expres- 
sion in axons is not increased commensurately with Schwann cell cx29 expression in $d h h-/-$ fibers.

Dhh/shi double null mice have increased numbers of SLIs compared with single null mice

The fact that SLI numbers are increased in both $d h h$ and shi (MBP) mutants led us to ask whether these conditions were linked.

To investigate this genetically, we crossed $d h h$ null mice with shi mice to obtain mice that were null for both $d h h$ and $M B P$. We reasoned that if Dhh and MBP acted along an identical pathway to control SLIs, there should be little or no increase in the number of SLIs in the double mutants compared with the single mutant mice. In contrast, if Dhh and MBP were components of two relatively independent and parallel mechanisms, the number of SLIs should be further increased. Eleven double null mice were obtained. Five were used to make teased nerve preparations and for electron microscopy. It was found that the distance between SLIs was substantially smaller in $\mathrm{dhh} /$ shi double null nerve fibers than in either of the single null mice both at 3 and 15 weeks ( $n=2$ for each genotype at each time point) (Fig. 6C, Table 2). We also counted the number of SLIs along internodes and found that the number of SLIs per $100 \mu \mathrm{m}$ was elevated in the double mutant compared with the shi-/- at both time points (Table 2). As an additional measure of myelin disruption, we used electron micrographs of transversely sectioned nerves to compare the number of continuous, undisrupted compact myelin profiles (sheaths) in normal, $d h h-/-$, and double null mice ( $n=3$ per genotype) with the total number of myelinated fibers, which included profiles that contained incisures or nodal structures. We found that $92.3 \pm 1.20 \%$ of the total myelinated axon profiles in normal mice had intact sheaths, whereas the corresponding figure was $75.7 \pm 3.93 \%$ in $\mathrm{dhh}-\mathrm{/}-$ mice. In the double mutants, however, only $23 \pm 2.52 \%$ of total myelinated profiles had intact sheaths. This measure of myelin compactness therefore confirms the difference between single and $d h h / s h i$ double mutant nerves revealed by measuring SLI intervals or counting SLI numbers.

Together, these results suggest that Dhh and MBP control SLI numbers by distinct and relatively independent mechanisms. We also confirmed that the number of SLIs in shi+/- mice was intermediate between the wild-type and shi-/- mice (data not shown) (Smith-Slatas and Barbarese, 2000). Toluidine blue semithin sections revealed that the nerves of the double null mice, like those of $d h h-/-$ mice, were arranged in mini-fascicles (Fig. $6 A, B)$.

\section{Nonmyelinating Schwann cells and unmyelinated axons are affected in $d h h-/-$ nerves}

In transverse sections of $d h h-/-$ nerves, we noted a large number of unmyelinated axons in a 1:1 ratio with a single Schwann cell, whereas nonmyelinating cells with large numbers of axons were seldom seen (Fig. 7A). This was confirmed by using electron microscopy to count the number of unmyelinated axons in a 1:1, $1: 2$, etc., ratio with Schwann cells in an entire transverse section of sciatic nerve from 2 - to 4 -month-old $d h h-/-$ and $d h h+/-$ lit-
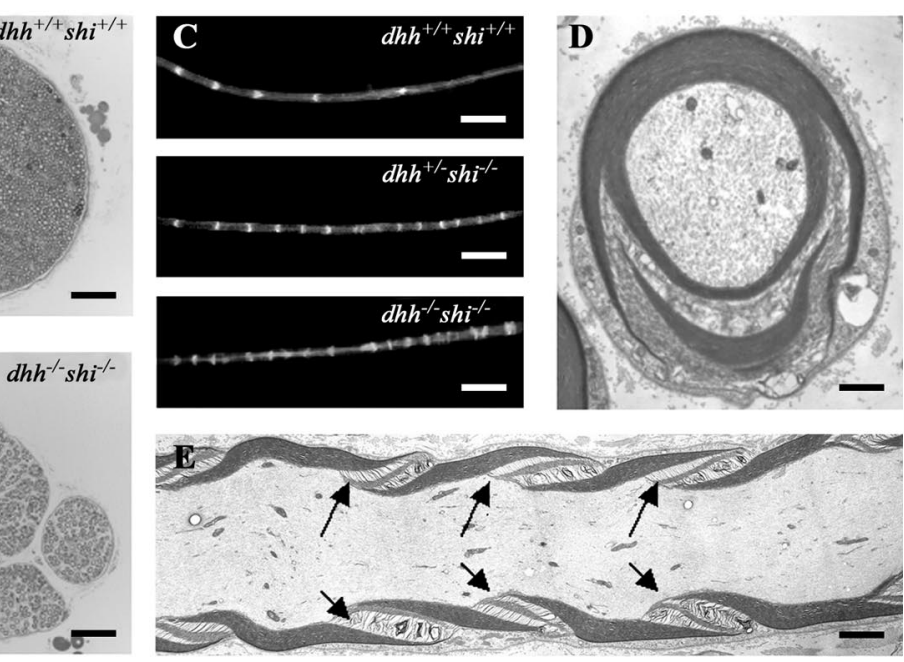

Dhh $-/-/$ shi-/ - double null sciatic nerves have increased numbers of SLI. $A, B$, Semithin toluidine blue-stained micrograph showing a complex SLI in a transverse section of double null nerve. $\boldsymbol{E}$, Electron micrograph of multiple SLIs (arrows) in a double mutant nerve shown in a longitudinal section. Scale bars: $\boldsymbol{A}, \boldsymbol{B}, 70 \mu \mathrm{m} ; \boldsymbol{C}, 66 \mu \mathrm{m} ; \boldsymbol{D}, 0.9 \mu \mathrm{m} ; \boldsymbol{E}, 0.7 \mu \mathrm{m}$.

termates ( $n=3$ per genotype) (Fig. $7 B$ ). This showed that the percentage of axons in a 1:1 ratio was highly elevated in $d h h-/-$ nerves. In line with this, the number of axons found in groups of 10 or larger was lower in the $d h h-/-$ nerves. Axon/Schwann cell units containing two to nine axons were present in similar numbers and accommodated $40-45 \%$ of axons in both genotypes (Fig. $7 A, B$ ). To determine whether the total number of unmyelinated axons was altered in the absence of Dhh, we used the electron microscope to count the total number of unmyelinated axons in the tibial branch of the sciatic nerve at 2, 4, and 5.5 months of age. In $d h h+/+$ mice, there were $4335.33 \pm 47.88$ unmyelinated axons, and in $d h h-/-$ mice, there were $2807.67 \pm 138.81$ unmyelinated axons. Comparison revealed a statistically significant difference ( $p<0.001$; Student's $t$ test) in the number of unmyelinated axons in $d h h-/-$ nerves.

Thus, in addition to the changes in myelinating Schwann cells (see above), the nonmyelinating Schwann cells are also altered in the absence of Dhh, a fact that is likely to be related to the expression of Ptc2 receptors on these cells (Bajestan et al., 2006).

\section{In Schwann cells, ptc1 is not regulated in response to Hh signaling}

We showed previously that in developing peripheral nerve, the Hh receptor $p t c 1$ was localized at highest levels in the perineurial cells surrounding nerve fibers. Furthermore, its expression level in these cells of fibroblastic origin was upregulated by Dhh, as would be expected, because Hhs normally upregulate ptc1 expression in target cells (Parmantier et al., 1999). In view of the Schwann cell phenotype reported here, we wanted to determine whether Schwann cells, in addition to expressing $d h h$, also expressed $p t c 1$ receptors that were responsive to Hh signaling.

Purified neonatal mouse Schwann cells or nerve-derived fibroblasts were cultured with Hh ligands or agonists (FrankKamenetsky et al., 2002) for 3 and 24 h. RT-PCR revealed that Schwann cells expressed detectable levels of $p t c 1$, but unlike nerve fibroblastic cells, they did not upregulate $p t c 1$ expression in response to Hh signals (Fig. 7C). The reason for this is unknown. Ptc2 receptors are also expressed in peripheral nerve where they 
Table 2. The number of SLIs in double mutants

\begin{tabular}{|c|c|c|c|c|c|c|}
\hline & Dhh $+/+/$ shi $+/+$ & $d h h+/-/ s h i+/-$ & shi+/- & shi-/- & $d h h-/-$ & Dhh $-/-/$ shi-l- \\
\hline \multirow[t]{2}{*}{ Fiber diameter } & $7.42 \pm 0.10$ & $6.94 \pm 0.84$ & $6.98 \pm 0.93$ & $7.04 \pm 0.93$ & & $6.86 \pm 0.13$ \\
\hline & $8.69 \pm 0.22$ & $9.03 \pm 0.11$ & & $8.41 \pm 0.16$ & $9.19 \pm 0.16$ & $7.96 \pm 0.14$ \\
\hline \multirow[t]{2}{*}{ Distance between SLIs } & $40.64 \pm 1.66$ & $27.47 \pm 0.95$ & $32.44 \pm 1.43$ & $16.73 \pm 0.37$ & & $13.92 \pm 0.38^{*}$ \\
\hline & $41.53 \pm 2.04$ & $31.64 \pm 0.74$ & & $19.51 \pm 0.44$ & $23.70 \pm 0.73$ & $12.90 \pm 0.21^{* * * *}$ \\
\hline \multirow[t]{2}{*}{$\mathrm{SLI} / 100 \mu \mathrm{m}$} & $2.02 \pm 0.11$ & $2.89 \pm 0.12$ & $2.21 \pm 0.12$ & $4.77 \pm 0.17$ & & $6.42 \pm 0.31^{*}$ \\
\hline & $2.36 \pm 0.18$ & $3.04 \pm 0.18$ & & $4.79 \pm 0.20$ & $4.17 \pm 0.26$ & $7.87 \pm 0.2^{*, * *}$ \\
\hline
\end{tabular}

Nerve fiber analysis of the sciatic nerves of littermates of the indicated genotypes at 3 weeks (bold letters) and 15 weeks of age. Note that double null nerves have shorter SLI distances and higher numbers of $\mathrm{SLI}$ s per $100 \mathrm{\mu m}$ than the single mutants. ${ }^{*} p<0.001$ versus shi $-/-;{ }^{* *} p<0.001$ versus shi $-/-$ (Mann-Whitney test).

are found selectively on nonmyelinating Schwann cells in teased preparations of normal adult nerves (Bajestan et al., 2006).

In so far as the absence of upregulation of $p t c 1$ can be taken to indicate nonfunctionality of the $p t c 1$ signaling pathway and the fact that $p t c 1$ mRNA levels are very low in adult nerves (Parmantier et al., 1999), these observations suggest that the effects of Dhh on myelinating Schwann cells are most likely to be indirect, perhaps via Dhh-induced signals from perineurial cells, rather than autocrine, whereas the effects of Dhh on nonmyelinating cells are likely to be via Ptc2.

\section{Blood vessels in peripheral nerves of $d h h-/-$ mice are abnormally permeable}

In $d h h-/-$ nerves, the molecular and cellular composition of the endoneurium is likely to be altered because of the breakdown of the tissue-nerve barrier (Parmantier et al., 1999). The endoneurial capillary-nerve barrier (blood-nerve barrier) constitutes another protective mechanism for endoneurial nerve fibers. We therefore tested whether the blood vessels in $d h h-/-$ mice were abnormally leaky, using permeability to EBA as an indicator (Kristensson and Olsson, 1971).

EBA was injected into the jugular vein of $d h h+/+$ and $d h h-/-$ mice under general anesthesia and allowed to circulate for $30 \mathrm{~min}$ or $3 \mathrm{~h}$. The mice were then killed, and the sciatic nerves and the brain from each animal were fixed, sectioned, and viewed under the fluorescence microscope (Fig. 8). In the brain, EBA was confined to blood vessels at both time points, and no differences were seen between $d h h+/+$ and $d h h-/-$ animals. In the sciatic nerve of control mice, EBA was associated with the perineurium/ epineurium, presumably reflecting the normal permeability of epineurial vessels. In the endoneurium, EBA was, however, confined to blood vessels at both time points, demonstrating the existence of the blood-nerve barrier in $d h h+/+$ nerves. But in $d h h-/-$ nerves, EBA distribution was markedly different. In this case, EBA was present throughout the nerve at both time points.

Thus, the double protection offered to endoneurial nerve fibers by the perineurial tissue-nerve barrier and the blood-nerve barrier is absent in $d h h-/-$ mice. The permeability of the bloodbrain barrier is, however, independent of Dhh signaling. Although this is likely to have adverse effects on peripheral nerve fibers, it is probably not a significant cause of the elevated SLI numbers in $d h h-/-$ fibers, because SLI numbers are elevated before the perineurial and vascular barriers develop fully (Kristensson and Olsson, 1971; Weerasuriya et al., 1990). Schwann cell-derived Dhh could also be involved in promoting vascularization of peripheral nerves (Kusano et al., 2004), although we did not find any obvious reduction in the number of blood vessels in $d h h-/-$ nerves (data not shown).

\section{Uninjured dhh-/- nerves show age-dependent axonal degeneration and myelin breakdown}

The loss of myelinated axons indicated that these uninjured $d h h-/-$ nerves suffered spontaneous axonal degeneration, perhaps accompanied by regeneration.

To investigate this for myelinated fibers, nerves from 2- to 6and 21-month-old $\mathrm{dhh}-/-$ mice were examined by electron microscopy ( $n=2$ per genotype per age group) (Fig. 9A). This revealed that $33 \pm 9.5(1.1 \pm 0.1 \%)$ of the myelinated axons (total axons counted, $2864 \pm 561)$ were degenerating at any one time in mutant nerves from 2- to 6-month-old mice, whereas no degenerating profiles (total axons counted, $4020 \pm 156$ ) were found in littermates. By 21 months, $12 \pm 1(0.3 \pm 0 \%)$ degenerating fibers were seen in wild-type controls (total axons counted, $4399 \pm$ 913), but they were still approximately four times more common, $50 \pm 2(1.2 \pm 0.2 \%)$, in $d h h-/-$ nerves (total axons counted, $4444 \pm 844)$. In $d h h-/-$ nerves, the number of degenerating profiles increased markedly from 2-6 months to 21 months.

In the $d h h-/-$ nerves, we also noted a number of axons that had thin myelin sheaths for their size (Fig. 9B). These were often associated with loops of redundant basal lamina (Fig. 9C). These features strongly indicate that these profiles represent regenerating axons in the early stages of myelination.

\section{Dhh $-/-$ nerves contain high numbers of macrophages and neutrophils}

Significant, ongoing axonal degeneration and myelin breakdown, as seen in $d h h-/-$ nerves, could be expected to be accompanied by elevated numbers of neutrophils and macrophages. To test this, frozen sections of $d h h-/-$ and $d h h+/+$ nerves $(n=2$ per genotype) were labeled with F4/80 antibody to reveal macrophages and with Gr-1 antibody to reveal neutrophils. This showed that in $d h h-/-$ nerves, the number of macrophages was elevated approximately fivefold and the number of neutrophils was elevated approximately fourfold compared with wild-type controls (Fig. 10A). By electron microscopy, macrophages and neutrophils were easily found in $d h h-/-$ nerves, but these cells were rarely seen in $d h h+/+$ nerves (data not shown).

These cell counts are likely to reflect a chronic inflammatory cellular response to the ongoing degeneration in $d h h-/-$ nerves.

\section{Degeneration and inflammatory cell recruitment in transected $d h h-/-$ nerves}

The elevated number of inflammatory cells, described above, is likely to be a part of the answer to why $d h h-/-$ nerves degenerate rapidly after transection (Bajestan et al., 2006), because for myelin breakdown, these nerves would be less reliant on the macrophage and neutrophil recruitment seen in normal nerves during the first few days after injury.

To examine macrophage and neutrophil recruitment, sciatic 


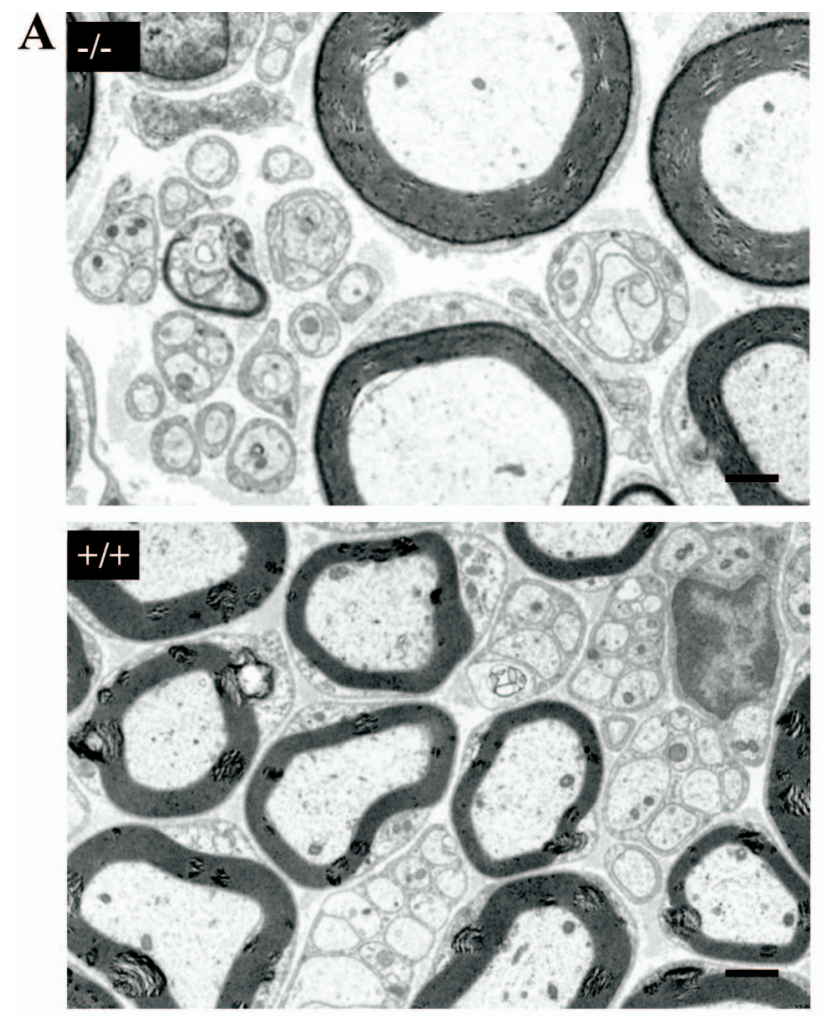

B

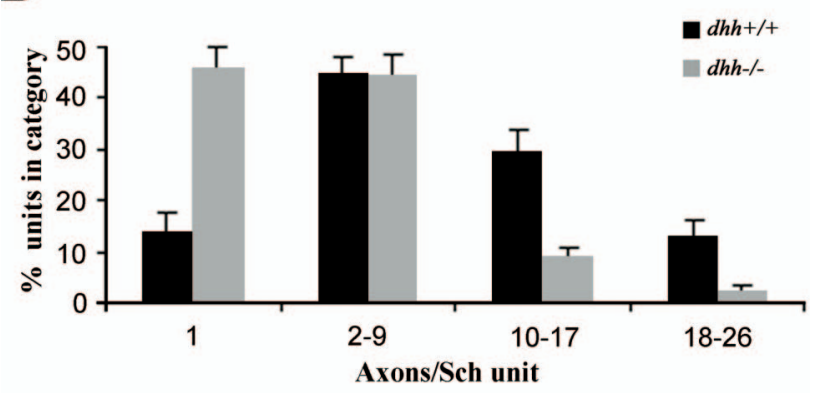

C

1hr $3 \mathrm{hr} \quad 24 \mathrm{hr}$

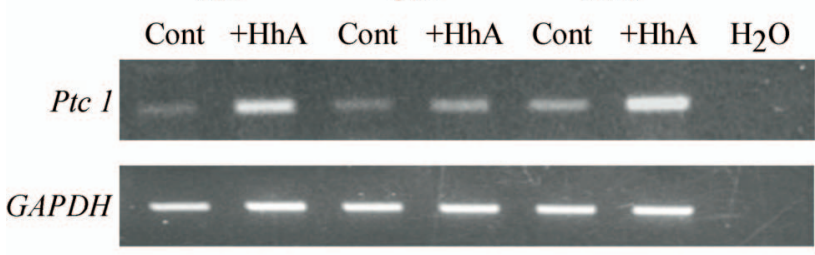

Mouse fibroblasts

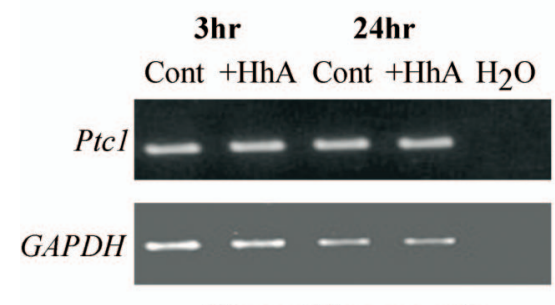

Mouse Schwann cells

Figure 7. A, Electron micrographs showing transverse sections of the sciatic nerve of 2-month-old mice, illustrating the typical difference in appearance of nonmyelinating Schwann cells in $d h h-/-$ and $d h h+/+$ animals. Scale bar, $1 \mu \mathrm{m}$. B , The percentage of the total number of small unmyelinated axons that is found in a 1:1 ratio and ratios of 1:2-9, etc. with nonmyelinating Schwann $(S c h)$ cells. Note the marked increase in the percentage of axons in a nerves of $d h h-/-$ and $d h h+/+$ mice were transected and processed for cell counts, whereas other nerves were fixed for electron microscopy or extracted for Western blotting to monitor nerve degeneration.

Accelerated degeneration of the distal stump was clearly evident by electron microscopy at 2 and $7 \mathrm{~d}$ after transection $(n=2$ per genotype per time point) (Fig. $11 \mathrm{~A}$ ). Two days after injury, the percentage of all myelinated fibers that were intact had collapsed axons, or collapsed axons and myelin was 45, 47, and 7\%, respectively, in $d h h+/+$ mice, whereas the corresponding figures in $d h h-/-$ nerve were 4,75 , and $20 \%$. Western blotting using TUJ1 antibody to detect neuron-specific $\beta$-tubulin showed that $2 \mathrm{~d}$ after transection, the levels of $\beta$-tubulin were markedly lower in the $d h h-/-$ nerves than in wild-type nerves, although at this early time point, $\mathrm{P}_{0}$ levels were still unchanged (Fig. $11 \mathrm{~B}$ ). This confirms the rapid degeneration of axons in the mutants and agrees with previous observations that axonal degeneration precedes loss of myelin (Koeppen, 2004).

Counts of macrophages using F4/80 antibodies showed that in $d h h+/+$ nerves, their number had increased sevenfold to eightfold at $2 \mathrm{~d}$ after cut, in line with previous observations (Perry et al., 1987; Clemence et al., 1989), whereas in mutant nerves, macrophage numbers increased only approximately twofold to reach comparable numbers to those seen in cut $d h h+/+$ nerve (Fig. $10 \mathrm{~B})$. Neutrophil invasion is one of the earliest responses to nerve injury and is followed slightly later by the arrival of macrophages (Perkins and Tracey, 2000). Counts of neutrophils using Gr-1 antibodies revealed that in $d h h+/+$ nerves, their number had risen sevenfold to eightfold $2 \mathrm{~d}$ after transection. In $\mathrm{dhh}-/-$ nerves, however, neutrophil numbers remained unaltered.

Uninjured $d h h-/-$ nerves are organized into mini-fascicles, not found in controls (Parmantier et al., 1999). Surprisingly, in injured $d h h-/-$ nerves, the number of mini-fascicles increased rapidly, even from this high baseline, and was elevated by almost $50 \%$ on day 2 after transection (Fig. $11 A$ ). Thus, the number of mini-fascicles in entire transverse sections of $d h h-/-$ uninjured nerves was 140, in $2 \mathrm{~d}$ transected nerves (Fig. 11A) was 222, and in $7 \mathrm{~d}$ transected nerves was $260(n=2)$. Wild-type nerves show slow reorganization into mini-fascicles associated with nerve transection (Bradley et al., 1998).

\section{Discussion}

This study shows compound tissue abnormalities in nerves that lack the signaling protein Dhh. This indicates that the cell-cell signaling networks that control tissue maturation and homeostasis in peripheral nerves include, and are crucially dependent on, Dhh. Because Dhh is derived from glial cells, these observations also make the general point that in the peripheral nervous system, glial signals are essential for broad-spectrum tissue integrity. This is likely to apply to glial cells more generally, although, in vivo, signaling molecules with this function in mammalian glia do not appear to have been identified previously.

We found that myelinated Schwann cells in $d h h-/-$ mice have more than double the normal number of SLIs. Although SLI numbers are also increased in MBP-deficient shi mice (Gould et

1:1 ratio with a Schwann cell in $d h h-/-$ nerves and the decrease in the Schwann cell units containing large numbers of axons. C, RT-PCR analysis showing that ptc 1 mRNA in cultured Schwann cells is not upregulated in response to hedgehog ligands $(\mathrm{Hh} A)$ in contrast to that seen in fibroblasts. Dhh protein (40 nM) was applied to Schwann cells, and the Hh agonist Cur019956767 (40 nM) was applied to fibroblasts. GAPDH is shown to indicate that samples are equally loaded. Cont, Control. Mean values \pm SEM are shown. 


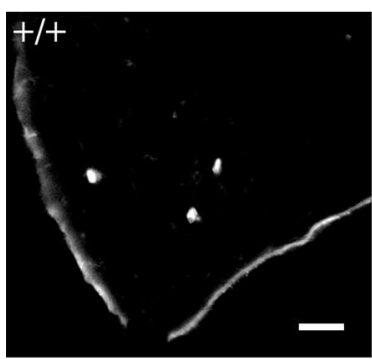

Sciatic Nerve
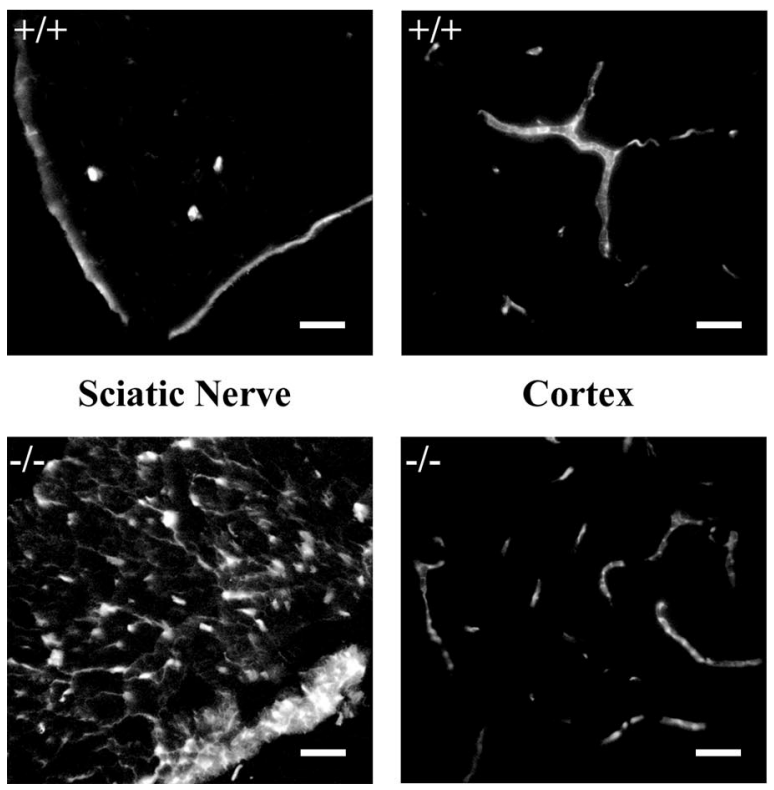

Cortex

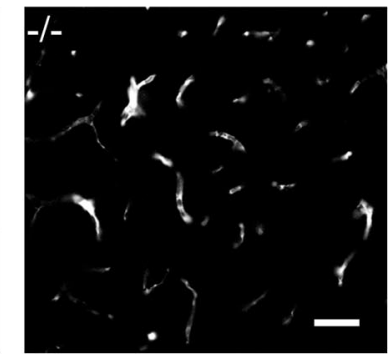

Figure 8. Endoneurial blood vessels in $d h h-/-$ nerves are permeable to dyes. Comparison of permeability to EBA in $d h h+/-$ and $d h h-/-$ mouse tissues is shown. Left column, Sciatic nerve. Note the labeling throughout the nerve in the $d h h-/-$ nerve (bottom), whereas in the $d h h+/-$ nerve, EBA is confined to the epineurium and three capillaries within the endoneurium. Middle and right columns, Labeling is confined to capillaries in both the cortex and cerebellum and does not differ between $d h h+/-$ and $d h h-/-$ mice. Scale bars, $50 \mu \mathrm{m}$.

al., 1995), we found that the number of SLIs is substantially increased again in $\mathrm{dhh} / \mathrm{sh}$ i double mutants, which suggests that Dhh and MBP are likely to control SLI numbers through distinct mechanisms. One of the molecular components of SLI, cx29, is strikingly elevated in $d h h-/-$ nerves. Nonmyelinating Schwann cells (in Remak fibers) are also affected, because Remak fibers with large numbers of axons are reduced in number, whereas cells that envelop a single axon only are more numerous. The total number of unmyelinated axons is also reduced by one-third, whereas myelinated axons are lost, albeit to a lesser extent. We show that the blood-nerve barrier is permeable in $\mathrm{dhh}-/-$ mice, a finding that parallels the breakdown of the perineurial diffusion barrier in these animals (Parmantier et al., 1999). In $d h h-/-$ nerves, the number of resident macrophages and neutrophils is also elevated. Significantly, uninjured $d h h-/-$ nerves contain a substantial number of degenerating myelinated fibers, which increases with age. They also contain regenerating axons. In addition to this age-dependent neuropathy, degeneration of injured nerves is more rapid in $d h h$ animals than in controls.

Although Dhh is expressed in myelinating Schwann cells, Hh receptors are mainly found on the perineurial cells $(p t c 1)$ and nonmyelinating Schwann cells ( $p t c 2)$. Very low levels of ptc1 are seen on Schwann cells in tissue sections, although they can be detected on neonatal cells in culture by RT-PCR. Even in this case, however, they are not upregulated in response to Hh agonists as expected for $p t c 1$ and as seen for $p t c 1$ in fibrobasts. This argues against an autocrine Dhh circuit in myelinating Schwann cells. A more likely mechanism is indicated by the action of Ihh in cartilage. In this case, Ihh from chondrocytes acts on $p t c 1$ receptors in the perichondrium that surrounds the cartilage and induces the expression of a second signal that acts back on the chondrocytes (Vortkamp et al., 1996). It is therefore possible that Schwann cell-derived Dhh acts on the perineurium that surrounds the nerve, inducing signals that, in turn, act back on Schwann cells and perhaps other elements in the nerve.
It will be a complex task to untangle Dhh-dependent cell-cell signaling networks in peripheral nerves and to define the causal sequences that translate the absence of Dhh in myelinating Schwann cells into the set of tissue changes we have observed. At this point, we can only speculate. The breakdown of the tissue-nerve and blood-nerve barriers is likely to alter the chemical composition of the endoneurial space and therefore the microenvironment of the axon-Schwann cell units (Olsson, 1990; Beamish et al., 1991; Sinnreich et al., 2005). This, however, is unlikely to be the cause of the adverse changes in myelinating Schwann cells, the increase in SLI, because this is already evident at P10, which is before these barriers are effective (Kristensson and Olsson, 1971; Weerasuriya et al., 1990). Similarly, the abnormalities seen in nonmyelinating fibers are likely to relate to the striking and selective expression of ptc2 Hh receptors on these cells (Bajestan et al., 2006). Schwann cell defects, in turn, are likely to contribute to the axon loss seen in dhh $-/-$ nerves. In the case of myelinating axons, this is accompanied by regeneration as we have observed. But it is also plausible to suggest that the large reduction in unmyelinated axons, likely caused by a lack of ptc2 activation in these cells, leads to the observed remodeling of Remak fibers to accommodate fewer axons per Schwann cell.

It is unclear to what extent the elevated number of neutrophils and macrophages in uncut $d h h-/-$ nerves is attributable to the absence of vascular and perineurial barriers to their entry, or to what degree they are attracted by the ongoing fiber degeneration. The presence of these cells could contribute to fiber instability, because in another model of demyelinating peripheral neuropathy (i.e., $\mathrm{P}_{0}+1-$ heterozygote mice) there are increased numbers of macrophages within the endoneurium and both resident and blood-borne macrophages play an active role in the demyelination (Carenini et al., 2001; Maurer et al., 2003). In cut $d h h-/-$ nerves, the relatively rapid disappearance of TUJ1 only $2 \mathrm{~d}$ after injury indicates abnormally fast axonal degeneration, and there is a concomitant increase in myelin degradation. This accelerated deterioration in injured nerves may be caused partly by the same factors that cause ongoing axon loss in intact $d h h-/-$ nerves. But it is also likely that the increased numbers of resident macrophages and neutrophils play a part, because these cells are known to be crucial to the degenerative response (Scheidt et al., 1986; Coleman and Perry, 2002). The effect is the converse of that observed in the C57BL/Wld mouse in which a chromosome translocation results in delayed axonal degeneration and myelin degradation (Lunn et al., 1989; Coleman and Perry, 2002).

Extensive investigation of molecules known to be associated with SLI revealed that $\mathrm{cx} 29$ was upregulated at both the mRNA and protein level in $d h h-/-$ nerves. This is intriguing because in adult nerves, cx29 is localized to the innermost layers of the myelin sheath, showing a striking coincidence with $\mathrm{K}_{\mathrm{V}} 1.2$ potassium channels in the underlying axonal membrane (Altevogt et al., 2002; Li et al., 2002). Our immunohistochemical experiments failed, however, to show any increase in $\mathrm{K}_{\mathrm{V}} 1.2$ channels corresponding to the strong cx29 upregulation. A small decrease was 
A

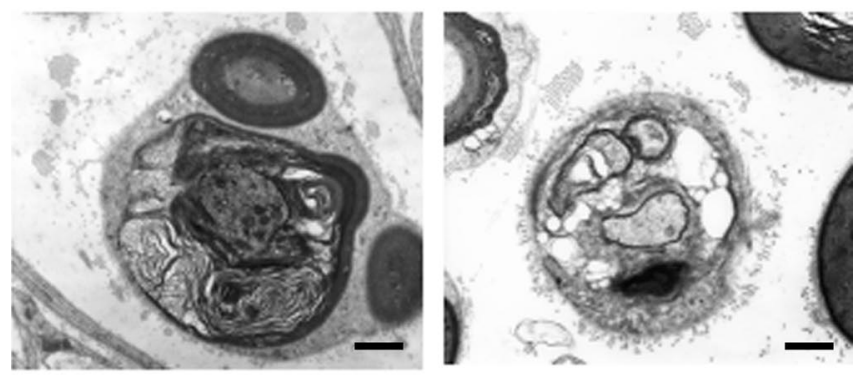

B
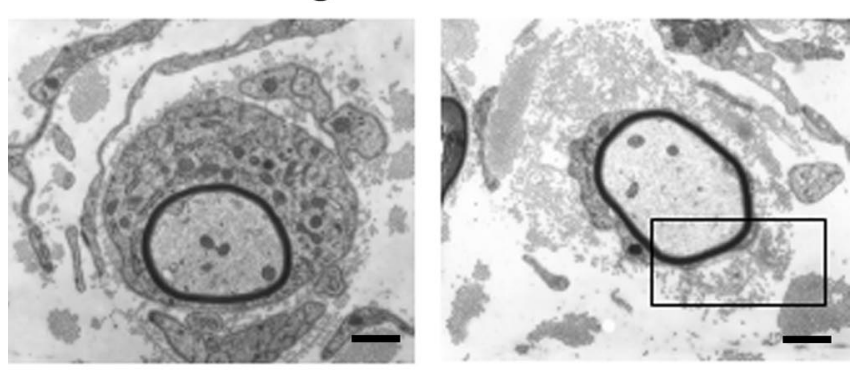

C

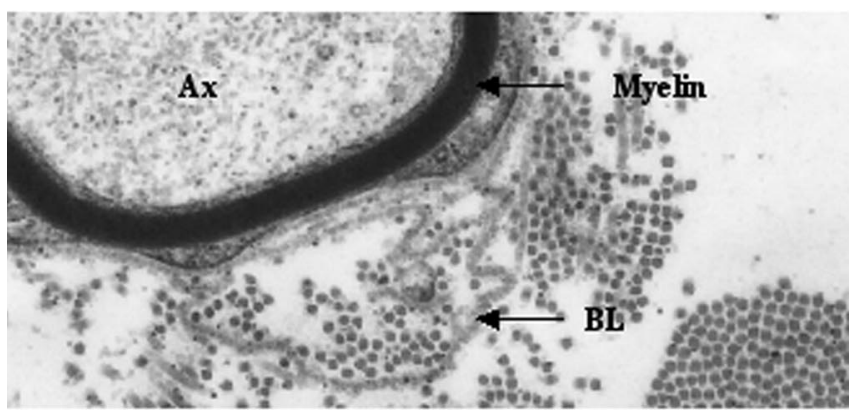

Figure 9. Dhh $-/-$ nerves contain degenerating and regenerating nerve fibers. $A$, Electron micrographs showing two profiles of degenerating fibers. Left, Shrunken axon surrounded by myelin debris. Right, Shrunken axon surrounded by a vacuolated Schwann cell. B, Two profiles of regenerating axons with thin myelin sheaths relative to the axon diameter. $C$, Enlargement of the boxed in area in $\boldsymbol{B}$. Note the redundant basal lamina (BL) associated with a thinly myelinated fiber. Ax, Axon. Scale bars: $A, B, 1.8 \mu \mathrm{m}$.

UNCUT

Macrophages Neutrophils

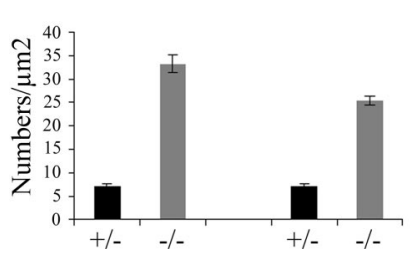

Figure 10. Normal and transected $d h h-/-$ nerves contain increased numbers of macrophages and neutrophils. $A$, Comparison of macrophage and neutrophil numbers in intact $d h h-/-$ and null nerves. Note the significant increase in the number of macrophages ( $p<$ $0.004)$ and neutrophils $(p<0.005)$ in the $d h h-/-$ nerves. $\boldsymbol{B}$, Comparison of macrophage and neutrophil numbers in the distal stump of $d h h+/-$ and null nerves $2 \mathrm{~d}$ after transection. Both normal and mutant nerves show increased macrophage numbers. Transected normal nerves show a substantial increase in neutrophil numbers as expected, but neutrophil numbers in cut $d h h-/-$ nerves are little changed. Mean values \pm SEM are shown.

\section{$\mathbf{A}$}
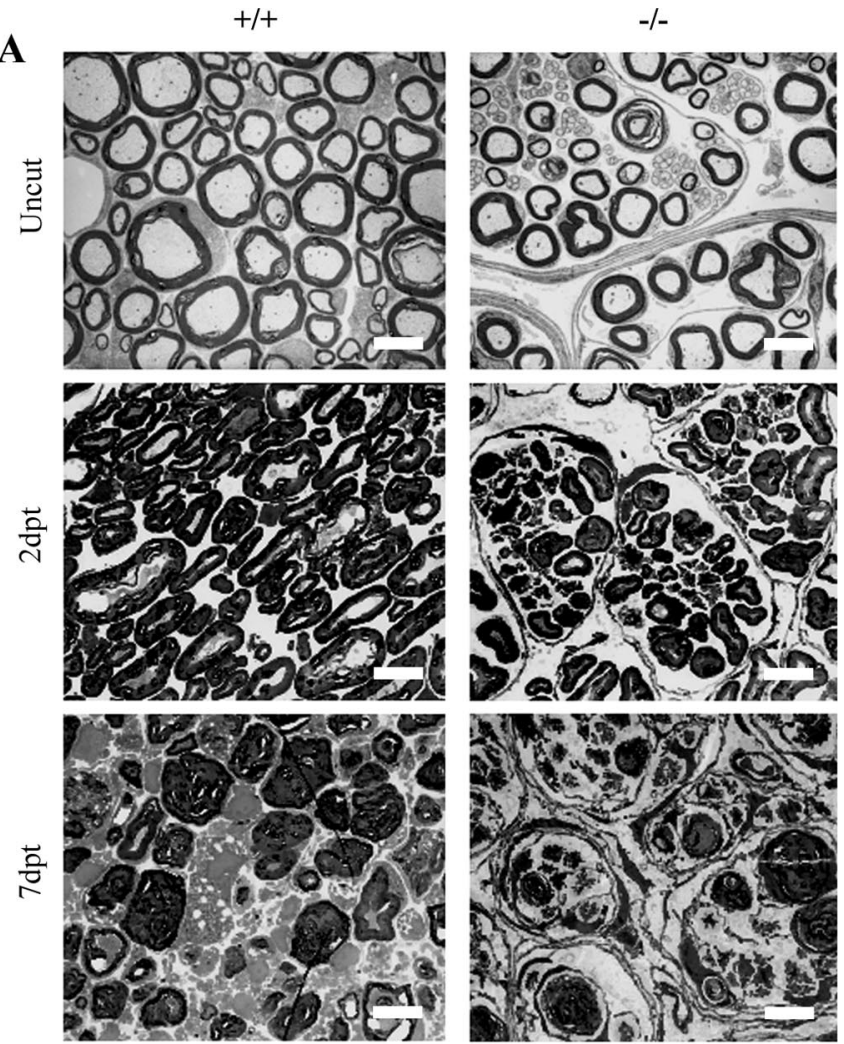

$+/-$

B

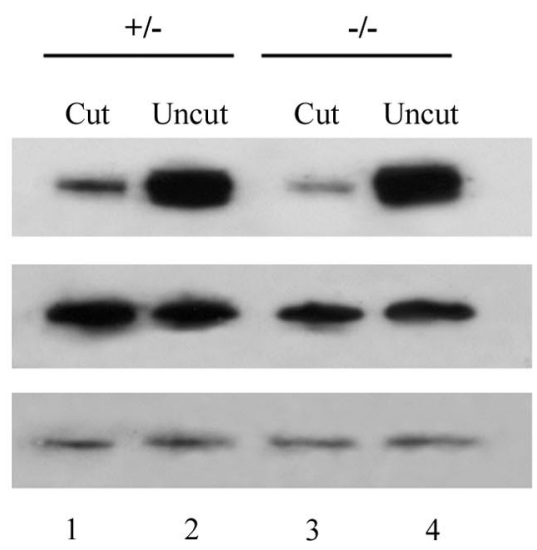

Figure 11. Dhh $-/-$ fibers degenerate rapidly after injury, and the number of minifascicles increases. A, Low-power view of nerves 2 and $7 \mathrm{~d}$ post-transection (2dpt and $7 \mathrm{dpt}$ ). At both time points, the $d h h-/-$ nerve shows more advanced degeneration, although the difference is more pronounced at $2 \mathrm{~d}$. Note that an increased number of mini-fascicles is present in the dhh $-/-$ nerve at 2 and $7 \mathrm{~d}$. Scale bars, $5.5 \mu \mathrm{m} . \boldsymbol{B}$, TUJ1 (TUJ) immunoblotting reveals that TUJ1 levels, an indicator of axon integrity, show a more marked decrease in $d h h-/-$ nerves than in $d h h+/-$ nerve at $2 \mathrm{~d}$ after transection. $P_{0}$ levels are not markedly altered at this time.

observed in MBP (but not mRNA) levels at older ages only, with minimal changes in the MAG protein level. This contrasts with the findings of Smith-Slatas and Barbarese (2000) in shi mice, in which increased MAG and cx32 protein levels were found in shi nerves relative to wild-type nerves, although mRNA levels were unaltered. We did not see an increase in cx32 mRNA levels or in protein levels (data not shown). The SLI increase in $d h h-/-$ mice therefore seems to be mechanistically different from that in the shi mice, a conclusion we reinforced by the elevated SLI numbers in shh/shi double mutants. Increased SLIs are also seen in Schwann cells in Caspr/paranodin null mice (Bhat et al., 2001) 
and in the CNS in ceramide galactosyl transferase null mice (Dupree et al., 1998).

It has been reported recently that E-cadherin is required to stabilize SLIs and that dominant-negative mutations in E-cadherin that interfere with binding to p120 catenin cause destabilization and disappearance of SLIs (Tricaud et al., 2005). Because we did not find an increase in E-cadherin levels on Western blot, we think it unlikely that alterations in E-cadherin levels are responsible for the increased number of SLIs.

It is of great interest that Dhh levels are reduced in experimental diabetic neuropathy (Calcutt et al., 2003). The present finding that loss of Dhh leads to a broad-spectrum neuropathy indicates that the Dhh reduction in experimental diabetic neuropathy may be a significant cause of the pathological changes seen in that model. This interpretation is also strongly supported by the finding that external Shh, which activates similar signaling pathways to Dhh, restores nerve function to nondiabetic levels and enhances nerve regeneration after injury (Pepinsky et al., 2002; Calcutt et al., 2003; Kusano et al., 2004).

Furthermore, it is noteworthy that a number of the faults caused by Dhh deficiency and described here have been identified previously as age-related changes. These include axonal loss that involves substantially greater reduction in the number of unmyelinated axons than myelinated ones, the presence of regenerating myelinated fibers, increased numbers of resident macrophages, widening of individual SLIs, increase in SLI number, and a shift toward fewer axons per nonmyelinating Schwann cell in Remak fibers (Kanda et al., 1991; Ceballos et al., 1999; Tabata et al., 2000).

Together, these observations lend strong support to the conclusion drawn from the present study that glial-derived Dhh is an essential developmental and trophic signal in peripheral nerves. They also raise the possibility that a failure of this system contributes to nerve pathology and the nerve deterioration that accompanies aging.

\section{References}

Altevogt BM, Kleopa KA, Postma FR, Scherer SS, Paul DL (2002) Connexin 29 is uniquely distributed within myelinating glial cells of the central and peripheral nervous systems. J Neurosci 22:6458-6470.

Archelos JJ, Roggenbuck K, Schneider-Schaulies J, Linington C, Toyka KV, Hartung HP (1993) Production and characterization of monoclonal antibodies to the extracellular domain of P0. J Neurosci Res 35:46-53.

Arroyo EJ, Xu YT, Zhou L, Messing A, Peles E, Chiu SY, Scherer SS (1999) Myelinating Schwann cells determine the internodal localization of Kv1.1, Kv1.2 Kvbeta2 and Caspr. J Neurocytol 28:333-347.

Bajestan SN, Umehara F, Shirahama Y, Itoh K, Sharghi-Namini S, Jessen KR, Mirsky R, Osame O (2006) Desert hedgehog-patched 2 expression in peripheral nerves during Wallerian degeneration and regeneration. J Neurobiol 66:243-255.

Balice-Gordon RJ, Bone LJ, Scherer SS (1998) Functional gap junctions in the Schwann cell myelin sheath. J Cell Biol 142:1095-1104.

Beamish NG, Stolinski C, Thomas PK, King RH (1991) Freeze-fracture observations on normal and abnormal perineurial tight junctions: alterations in diabetic polyneuropathy. Acta Neuropathol (Berl) 81:269-279.

Bhat MA, Rios JC, Lu Y, Garcia-Fresco GP, Ching W, St Martin M, Li J, Einheber S, Chesler M, Rosenbluth J, Salzer JL, Bellen HJ (2001) Axonglia interactions and the domain organisation of myelinated axons requires neurexinIV/Caspr/paranodin. Neuron 30:369-383.

Bitgood MJ, Shen L, McMahon AP (1996) Sertoli cell signaling by Desert hedgehog regulates the male germline. Curr Biol 6:298-304.

Bradley JL, Abernethy DA, King RH, Muddle JR, Thomas PK (1998) Neural architecture in transected rabbit sciatic nerve after prolonged nonreinnervation. J Anat 192:529-538.

Calcutt NA, Allendoerfer KL, Mizisin AP, Middlemas A, Freshwater JD, Burgers M, Ranciato R, Delcroix JD, Taylor FR, Shapiro R, Strauch K, Dudek H, Engber TM, Galdes A, Rubin LL, Tomlinson DR (2003) Therapeutic efficacy of sonic hedgehog protein in experimental diabetic neuropathy. J Clin Invest 111:507-514.

Carenini S, Maurer M, Werner A, Blazyca H, Toyka KV, Schmid CD, Raivich G, Martini R (2001) The role of macrophages in demyelinating peripheral nervous system of mice heterozygously deficient in $\mathrm{P}_{0}$. J Cell Biol 152:301-308.

Ceballos D, Cuadras J, Verdu E, Navarro X (1999) Morphometric and ultrastructural changes with ageing in mouse peripheral nerve. J Anat 195:563-576.

Chang B, Cho I, Brophy PJ (2000) A study on the immunocytochemical localization of neurofascin in rat sciatic nerve. J Vet Sci 1:67-71.

Chen S, Rio C, Ji RR, Dikkes P, Coggeshall RE, Woolf CJ, Corfas G (2003) Disruption of ErbB receptor signaling in adult non-myelinating Schwann cells causes progressive sensory loss. Nat Neurosci 6:1186-1193.

Clemence AM, Mirsky R, Jessen KR (1989) Non-myelin-forming Schwann cells proliferate rapidly during Wallerian degeneration in the rat sciatic nerve. J Neurocytol 18:185-192.

Coleman MP, Perry VH (2002) Axon pathology in neurological disease: a neglected therapeutic target. Trends Neurosci 25:532-537.

Colomar A, Robitaille R (2004) Glial modulation of synaptic transmission at the neuromuscular junction. Glia 47:284-289.

Dong Z, Sinanan A, Parkinson D, Parmantier E, Mirsky R, Jessen KR (1999) Schwann cell development in embryonic mouse nerves. J Neurosci Res 56:334-348.

Dupree JL, Coetzee T, Suzuki K, Popko B (1998) Myelin abnormalities in mice deficient in galactocerebroside and sulfatide. J Neurocytol 27:649-659.

Ebnet K, Suzuki A, Ohno S, Vestweber D (2004) Junctional adhesion molecules (JAMs): more molecules with dual functions? J Cell Sci 117:19-29.

Frank-Kamenetsky M, Zhang XM, Bottega S, Guicherit O, Wichterle H, Dudek H, Bumcrot D, Wang FY, Jones S, Shulok J, Rubin LL, Porter JA (2002) Small-molecule modulators of Hedghog signaling: identification and characterization of Smoothened agonists and antagonists. J Biol 1:10.

Garratt AN, Britsch S, Birchmeier C (2000) Neuregulin, a factor with many functions in the life of a Schwann cell. BioEssays 22:987-996.

Ghabriel MM, Allt G (1981) Incisures of Schmidt-Lanterman. Prog Neurobiol 17:25-28.

Gomez CM, Muggleton-Harris AL, Whittingham DG, Hood LE, Readhead C (1990) Rapid preimplantation detection of mutant (shiverer) and normal alleles of the mouse myelin basic protein gene allowing selective implantation and birth of live young. Proc Natl Acad Sci USA 87:4481-4484.

Gould RM, Byrd AL, Barbarese E (1995) The number of SchmidtLanterman incisures is more than doubled in shiverer PNS myelin sheaths. J Neurocytol 24:85-98.

Hall SM, Williams PL (1970) Studies on the "incisures" of Schmidt and Lanterman. J Cell Sci 6:767-791.

Hammerschmidt M, Brook A, McMahon AP (1997) The world according to hedgehog. Trends Genet 13:14-21.

Jessen KR (2004) Glial cells. Int J Biochem Cell Biol 36:1862-1867.

Jessen KR, Mirsky R (2005) The origin and development of glial cells in peripheral nerves. Nat Rev Neurosci 6:671-682.

Kanda T, Tsukagoshi H, Oda M, Miyamoto K, Tanabe H (1991) Morphological changes in unmyelinated nerve fibres in the sural nerve with age. Brain 114:585-599.

Koeppen AH (2004) Wallerian degeneration: history and clinical significance. J Neurol Sci 220:115-117.

Kristensson K, Olsson Y (1971) The perineurium as a diffusion barrier to protein tracers. Acta Neuropathol (Berl) 17:127-138.

Kusano KF, Allendoerfer KL, Munger W, Pola R, Bosch-Marce M, Kirchmair R, Yoon YS, Curry C, Silver M, Kearney M, Asahara T, Losordo DW (2004) Sonic hedgehog induces arteriogenesis in diabetic vasa nervorum and restores function in diabetic neuropathy. Arterioscler Thromb Vasc Biol 24:2102-2107.

Li X, Lynn BD, Olson C, Meier C, Davidson KG, Yasamura T, Rash JE, Nagy JI (2002) Connexin 29 expression, immunocytochemistry and freezefracture replica immunogold labelling (FRIL) in sciatic nerve. Eur J Neurosci 16:795-806.

Lunn ER, Perry VH, Brown MC, Rosen H, Gordon S (1989) Absence of Wallerian degeneration does not hinder regeneration in peripheral nerve. Eur J Neurosci 1:27-33.

Maurer M, Muller M, Kobsar I, Leonhard C, Martini R, Kiefer R (2003) 
Origin of pathogenic macrophages and endoneurial fibroblast-like cells in an animal model of inherited neuropathy. Mol Cell Neurosci 23:351-359.

Meier C, Dermietzel R, Davidson KG, Yasumura T, Rash JE (2004) Connexin32-containing gap junctions in Schwann cells at the internodal zone of partial myelin compaction and in Schmidt-Lanterman incisures. J Neurosci 24:3186-3198.

Morgan L, Jessen KR, Mirsky R (1991) The effects of cAMP on differentiation of cultured Schwann cells: progression from an early phenotype $\left(04^{+}\right)$to a myelin phenotype $\left(\mathrm{P}_{0}{ }^{+}, \mathrm{GFAP}^{-}, \mathrm{N}^{-\mathrm{CAM}^{-}}{ }^{-}\right.$NGF-receptor $\left.{ }^{-}\right)$ depends on growth inhibition. J Cell Biol 112:457-467.

Newman EA (2004) Glial modulation of synaptic transmission in the retina. Glia 47:268-274.

Nicholson SM, Gomes D, de Nechaud B, Bruzzone R (2001) Altered gene expression in Schwann cells of connexin32 knockout animals. J Neurosci Res 66:23-36.

Olsson Y (1990) Microenvironment of the peripheral nervous system under normal and pathological conditions. Crit Rev Neurobiol 5:265-311.

Parmantier E, Lynn B, Lawson D, Turmaine M, Sharghi Namini S, Chakrabarti L, McMahon AP, Jessen KR, Mirsky R (1999) Schwann cellderived Desert hedgehog controls the development of peripheral nerve sheaths. Neuron 23:713-724.

Pepinsky RB, Shapiro RI, Wang S, Chakraborty A, Gill A, Lepage DJ, Wen D, Rayhorn P, Horan GSB, Taylor FR, Garber EA, Galdes A, Engber TM (2002) Long-acting forms of Sonic hedgehog with improved pharmacokinetic and pharmacodynamic properties are efficacious in a nerve injury model. J Pharm Sci 91:371-387.

Perkins NM, Tracey DJ (2000) Hyperalgesia due to nerve injury: role of neutrophils. Neuroscience 101:745-757.

Perry VH, Brown MC, Gordon S (1987) The macrophage response to central and peripheral nerve injury. A possible role for macrophages in regeneration. J Exp Med 165:1218-1223.

Poliak S, Peles E (2003) The local differentiation of myelinated axons at nodes of Ranvier. Nat Rev Neurosci 4:968-980.

Poliak S, Matlis S, Ullmer C, Scherer SS, Peles E (2002) Distinct claudins and associated PDZ domain proteins form autotypic tight junctions in myelinating Schwann cells. J Cell Biol 159:361-372.

Ruiz i Altaba A, Nguyen V, Palma V (2003) The emergent design of the neural tube: prepattern, SHH morphogen and GLI code. Curr Opin Genet Dev 13:513-521.

Scheidt P, Waehneldt TV, Beuche W, Friede RL (1986) Changes of myelin proteins during Wallerian degeneration in situ and in Millipore diffusion chambers preventing active phagocytosis. Brain Res 379:380-384.

Schipke CG, Kettenmann H (2004) Astrocyte responses to neuronal activity. Glia 47:226-232.
Sinnreich M, Taylor BV, Dyck PJ (2005) Diabetic neuropathies. Classification, clinical features and pathophysiological basis. Neurologist 11:63-79.

Smith-Slatas C, Barbarese E (2000) Myelin basic protein gene dosage effects in the PNS. Mol Cell Neurosci 15:343-354.

Sohl G, Eiberger J, Jung YT, Kozak CA, Willecke K (2001) The mouse gap junction gene connexin 29 is highly expressed in sciatic nerve and regulated during brain development. Biol Chem 382:973-978.

Starkey PM, Turley L, Gordon S (1987) The mouse macrophage-specific glycoprotein defined by monoclonal antibody F4/80: characterization, biosynthesis and demonstration of a rat analogue. Immunology 60:117-122.

Tabata H, Ikegami H, Kariya K (2000) Spontaneous age-related peripheral neuropathy in B6C3F1 mice. J Toxicol Sci 25:95-104.

Takabatake T, Ogawa M, Takahashi TC, Mizuno M, Okamoto M, Takeshima K (1997) Hedgehog and patched gene expression in adult ocular tissues. FEBS Lett 410:485-489.

Trapp BD, Andrews SB, Wong A, O'Connell M, Griffin JW (1989) Colocalization of the myelin-associated glycoprotein and the microfilament components, F-actin and spectrin, in Schwann cells of myelinated nerve fibers. J Neurocytol 18:47-60.

Tricaud N, Perrin-Tricaud C, Bruses JL, Rutishauser U (2005) Adherens junctions in myelinating Schwann cells stabilize Schmidt-Lanterman incisures via recruitment of p120 catenin to E-cadherin. J Neurosci 25:3259-3269.

Tsuda M, Inoue K, Salter MW (2005) Neuropathic pain and spinal microglia: a big problem from molecules in "small" glia. Trends Neurosci 28:101-107.

Ullian EM, Christopherson KS, Barres BA (2004) Role for glia in synaptogenesis. Glia 15:209-216.

Umehara F, Tate G, Itoh K, Yamaguchi N, Douchi T, Mitsuya T, Osame M (2000) A novel mutation of desert hedgehog in a patient with $46, \mathrm{XY}$ partial gonadal dysgenesis accompanied by minifascicular neuropathy. Am J Hum Genet 67:1302-1305.

Vortkamp A, Lee K, Lanske B, Segre GV, Kronenberg HM, Tabin CJ (1996) Regulation of rate of cartilage differentiation by Indian hedgehog and PTH-related protein. Science 273:613-622.

Weerasuriya A, Curran GL, Poduslo JF (1990) Developmental changes in blood-nerve transfer of albumin and endoneurial albumin content in rat sciatic nerve. Brain Res 521:40-46.

Wrabetz L, Feltri ML, Quattrini A, Imperiale D, Previtali S, D’Antonio M, Martini R, Yin X, Trapp BD, Zhou L, Chiu SY, Messing A (2000) P0 glycoprotein overexpression causes congenital hypomyelination of peripheral nerves. J Cell Biol 148:1021-1034.

Zhang Q, Haydon PG (2005) Roles for gliotransmission in the nervous system. J Neural Transm 112:121-125. 